\title{
Bi-modular fusion proteins, a versatile therapeutic tool for re-directing a pre-existing Epstein-Barr virus antibody response towards defined target cells
}

\section{Benoît Gamain}

INSERM https://orcid.org/0000-0002-8255-2145

\section{Carine Brousse}

INSERM

\section{Nathan Rainey}

INSERM

\section{Béré Diallo}

INSERM

\section{Clara-Eva Paquereau}

INSERM

Alexandra Desrames

INSERM

Jolita Ceputyte

INSERM

Jean-Philippe Semblat

Institut National de la Transfusion Sanguine

Olivier Bertrand

INSERM

\section{Stéphane Gangnard}

INSERM

Jean-Luc Teillaud

INSERM https://orcid.org/0000-0003-4442-9565

Arnaud CHENE ( $\square$ arnaud.chene@inserm.fr)

INSERM

\section{Article}

Keywords: Epstein-Barr virus, polyclonal antibody response, bi-modular fusion proteins

Posted Date: June 29th, 2021

DOI: https://doi.org/10.21203/rs.3.rs-668626/v1 
License: (c) (i) This work is licensed under a Creative Commons Attribution 4.0 International License. Read Full License 
1 Bi-modular fusion proteins, a versatile therapeutic tool for re-directing a pre-

2 existing Epstein-Barr virus antibody response towards defined target cells

3

4 Benoît Gamain ${ }^{1}$, Carine Brousse ${ }^{1}$, Nathan Rainey ${ }^{1}$, Béré K. Diallo ${ }^{2}$, Clara-Eva Paquereau ${ }^{1}$, 5 Alexandra Desrames ${ }^{1}$, Jolita Ceputyte ${ }^{1}$, Jean-Philippe Semblat ${ }^{1}$, Olivier Bertrand ${ }^{1}$, Stéphane 6 Gangnard ${ }^{1}$, Jean-Luc Teillaud ${ }^{2}$, Arnaud Chêne ${ }^{1, *}$

7

$8 \quad{ }^{1}$ Université de Paris, Biologie Intégrée du Globule Rouge, UMR_S1134, Inserm, F-75015, Paris, 9 France.

$10{ }^{2}$ Laboratory «Immune Microenvironment and Immunotherapy », Inserm U.1135, Centre 11 d'immunologie et des maladies infectieuses (CIMI-Paris), Faculté de médecine, Sorbonne 12 Université, 91 boulevard de l'hôpital, 75013, Paris, France.

15 Running Title: Redirecting anti-EBV antibodies to the surface of target cells

18 "Correspondence:

19 Arnaud Chêne

20 INSERM (UMR_S1134)

216 rue Alexandre Cabanel, 75015 Paris, France

22 Phone : $0033(0) 144493108$

23 E-mail : arnaud.chene@inserm.fr 


\section{ABSTRACT}

25 Industrial production of therapeutic monoclonal antibodies is mostly performed in eukaryotic-

26 based systems, allowing post-translational modifications mandatory for their functional activity.

27 Nevertheless, the resulting elevated product cost limits therapy access to some patients, thus

28 increasing medical inequality. To address this limitation, we conceptualized a novel

29 immunotherapeutic approach aiming at redirecting a pre-existing polyclonal antibody response

30 against Epstein-Barr virus (EBV) towards defined target cells. We engineered bi-modular fusion

31 proteins (BMFPs), notably expressible in bacteria-based systems, comprising a Fc-deficient

32 binding moiety (Nanobody, scFv) specifically targeting an antigen expressed at the surface of a

33 target cell, fused to the P18 EBV antigen, which would recruit circulating endogenous anti-P18

34 IgG in individuals chronically infected by EBV. Opsonization of BMFP-coated target cells

35 efficiently triggered antibody-mediated clearing effector mechanisms in vitro, such as the

36 complement cascade, erythrophagocytosis by macrophages and Fc $\gamma$ RIII-mediated activation of

37 cellular pathways leading to antibody-dependent cell-mediated cytotoxicity (ADCC). When

38 assessed in a mouse tumour model, therapy performed with an anti-huCD20 BMFP significantly

39 led to increased mice survival and total cancer remission in some animals. These results indicate

40 that BMFPs are versatile tools for redirecting an Epstein-Barr virus pre-existing immune antibody

41 response towards pre-defined target cells and could represent potent and useful therapeutic

42 molecules to treat a broad range of diseases. 
48 The generation of therapeutic monoclonal antibodies (mAbs) is a tedious process, which

49 requires integrating the complex structural and biochemical features of the immunoglobulin (Ig)

50 molecules to achieve the desired effector functions and exhibit optimal in vivo efficacy ${ }^{1,2}$. Over

51 the past decades, mAbs developed to deplete target cells such as tumour cells or normal auto-

52 immune cells, for instance B cells in multiple sclerosis, have drawn a particular attention and

53 significant efforts have been undertaken to engineer Igs with optimized biological activity and

54 improved pharmacokinetic (PK) properties $^{3,4}$. Fragment crystallizable (Fc)-mutated and glyco-

55 engineered IgG have been developed to maximize their potential to trigger complement-dependent

56 cytotoxicity $(\mathrm{CDC})^{5,6}$, antibody-dependent cell-mediated cytotoxicity $(\mathrm{ADCC})^{7,8,9,10}$ and antibody-

57 dependent phagocytosis (ADP) ${ }^{11}$. Engineering of the Fc region of $\operatorname{IgG}$ have also permitted to

58 modulate the $\mathrm{pH}$-dependent affinity of some antibodies for neonate Fc receptors (FcRn),

59 consequently modifying the mAb PK properties and enhancing in vivo half-life ${ }^{12,13}$.

60 The vast majority of mAbs are repeatedly injected at high doses to achieve significant therapeutic

61 effects $^{14}$. MAb production has therefore to be achieved at very large scale. Today, most therapeutic

$62 \mathrm{mAbs}$ are expressed in eukaryotic cell-based systems, allowing the production of large quantities

63 of functional proteins presenting proper post-translational modifications such as glycosylation.

64 However, such systems require arduous selection processes and long production cycles resulting

65 in increased mAb manufacturing cost. Thus, the development of mAb-based therapies present

66 substantial hurdles and remains challenging in particular when long-term iterative treatments are

67 needed.

68 Thus, we envisioned the possibility of generating bi-modular fusion proteins (BMFPs) able to

69 redirect polyclonal endogenous high-affinity antibodies produced by memory B cells against 
70 Epstein-Barr virus (EBV) towards defined target cells. BMFPs could then be designed based on

71 an EBV antigen coupled to a specific ligand targeting a protein of interest on the surface of a target

72 cell. BMFPs could circumvent the need for all the complex engineering studies aiming at

73 improving the effector functions of a single monoclonal antibody and also allow the use of diverse

74 ligand units devoid of $\mathrm{Fc}$ chains, such as nanobodies, to trigger Fc $\gamma$-dependant antibody effector

75 mechanisms by recruiting anti-EBV polyclonal antibodies exhibiting a large spectrum of functions

76 and produced over long periods of time in individuals. Expressible in bacteria-based systems,

77 BMFPs could be produced at a low manufacturing cost as compared to current therapeutic mAbs,

78 offering broader access to patients.

79 EBV is a ubiquitous human herpes virus (HHV-4) that infects over $95 \%$ of the adult population

80 worldwide ${ }^{15}$. Following primary infection, EBV establishes a life-long persistent infection,

81 residing in a latent stage in memory $\mathrm{B}$ cells ${ }^{16}$. The persistence of the virus results from a fine

82 balance between viral latency, viral replication and host immune responses ${ }^{17}$. As a consequence,

83 infected individuals possess, all along their life, antibodies directed against various EBV antigens

84 including the conserved small capsomere-interacting protein P18 (ORF BFRF3) (Supplementary

85 Fig. 1), which is predominantly recognized by antibodies belonging to the IgG1 subclass ${ }^{18}$. This

86 human IgG subclass is the most commonly used for therapeutic antibodies, whatever their formats

87 (chimeric, humanized or fully human $\mathrm{mAbs})^{19}$, as it triggers and regulates effector immune

88 mechanisms via the binding of the $\mathrm{F} c \gamma$ region to the complement component $\mathrm{Cl}^{20,21}$ and to $\mathrm{Fc} \gamma$

89 receptors ( $\mathrm{F} c \gamma \mathrm{Rs})$ present at the surface of a broad range of leukocytes sub-populations ${ }^{22,23}$. It also

90 triggers pro-inflammatory or anti-inflammatory processes depending on the sialylation on the N-

91 linked glycan of the Fc region ${ }^{24}$. Thus, a P18-containing fusion molecule with a predefined binding

92 specificity could allow the recruitment of endogenous anti-P18 IgG1 antibodies at the surface of 
93 target cells and then trigger Fc-dependent and complement-dependent immune effector 94 mechanisms (Fig. 1).

95 As a proof of concept, we generated different sets of BMFPs comprising P18-derived antigens 96 fused to i) a nanobody $(\mathrm{Nb})$ directed against the Duffy Antigen Receptor for Chemokines (DARC)

97 expressed by mature red blood cells (RBCs) (Fig. 1 - model 1) and ii) a single-chain variable 98 fragment (scFv) directed against the human cluster of differentiation huCD20 expressed on most 99 mature B cells, which represents an exquisite target for antibody-based therapy of B cell-related 100 diseases (Fig. 1 - model 2). Following extensive biochemical characterisation, the ability of these 101 BMFPs to trigger target cell depletion through the recruitment of pre-existing anti-P18 antibodies 102 was assessed in various in vitro assays. An in vivo mouse tumour model, previously developed to 103 explore the vaccinal effect of anti-tumor antibodies ${ }^{25,26}$, was also used to evaluate the anti-tumor 104 capacity of anti-huCD20 BMFPs (Fig. 1 - model 2) injected into mice possessing anti-P18 105 antibodies.

106 We show herein that functional BMFPs against human RBCs and huCD20 cells bind 107 efficiently to their respective cellular targets and recruit anti-P18 antibodies at the cell surface, 108 triggering efficient immune effector functions. A strong in vitro RBC phagocytosis by 109 macrophage-like cells derived from Fc $\gamma \mathrm{RI}^{+} / \mathrm{RIIa}^{+}$monocytic leukemia THP1 cells was detected 110 when using anti-DARC BMFPs in combination with $\operatorname{IgG}$ present in the plasma of $\mathrm{EBV}^{+}$ 111 individuals. We also show that in vitro treatment of huCD20 $0^{+}$Burkitt's lymphoma cells with an 112 anti-huCD20 BMFP elicits a significant activation of the antibody-dependent complement cascade 113 and triggers a FcyRIII-mediated activation of the nuclear factor of activated T cells (NFAT) 114 pathway in an ADCC reporter assay in presence of plasma containing anti-P18 antibodies. Finally, 
115 we show an increased survival of P18-pre-immunized immunocompetent mice bearing huCD20 $0^{+}$

116 tumor cells following anti-huCD20 BMFP treatment.

117 All together, these results indicate that BMFPs are versatile tools for redirecting a pre-existing

118 Epstein-Barr virus immune antibody response towards pre-defined target cells and could represent

119 potent and useful therapeutic molecules in patients.

120

121 RESULTS

122 Engineering bi-modular fusion proteins (BMFPs) against DARC.

123 DARC, also known as Fy glycoprotein, is a promiscuous chemokine receptor abundantly present

124 at the surface of RBCs from individuals carrying the $\mathrm{FY}^{\mathrm{a}+} / \mathrm{FY}^{\mathrm{b}+}, \mathrm{FY}^{\mathrm{a}-} / \mathrm{FY}^{\mathrm{b}+}$ or $\mathrm{FY}^{\mathrm{a}} / \mathrm{FY}^{\mathrm{b}-}$

125 genotypes ${ }^{27}$ and was therefore considered as a molecular target of choice to generate a first set of

126 BMFPs targeting human erythrocytes in a proof of concept model (Fig. 1 - model 1). To generate

127 anti-DARC BMFPs, we chose a nanobody targeting the extracellular domain 1 (ECD1), which

128 specifically binds to $\mathrm{DARC}^{+}$human $\mathrm{RBCs}$ with high affinity ${ }^{28}$. The CA52 anti-DARC nanobody

129 (Nb- $\alpha \mathrm{DARC})$ was genetically fused to the N-terminus part of full-length P18 (P18FL) or of P18

130 fragments of different sizes (P18F2, P18F3, P18F4) (Fig. 2a, b). The resulting recombinant

131 constructs were expressed in E. coli SHuffle bacteria, which allow disulfide bond formation within

132 the cytoplasm ${ }^{29}$ (see the BMFP production scheme in Supplementary Fig. 2). Soluble non-

133 aggregated Nb- $\alpha$ DARC-P18F2, Nb- $\alpha$ DARC-P18F3, Nb- $\alpha$ DARC-P18F4 and Nb- $\alpha$ DARC could

134 be purified (>95\%) in large amounts by size exclusion chromatography (Fig. $\mathbf{2} \mathbf{c}, \mathbf{d})$ and used for

135 subsequent experiments. In contrast, the protein solubility of $\mathrm{Nb}-\alpha \mathrm{DARC}-\mathrm{P} 18 \mathrm{FL}$ was poor and 136 led to extensive aggregation during purification, preventing its further use (Fig. 2c). 
137 The biochemical and functional properties of $\mathrm{Nb}-\alpha \mathrm{DARC}$ and P18-derived polypeptides were then 138 sequentially examined. Nb- $\alpha$ DARC, Nb- $\alpha$ DARC-P18F2, Nb- $\alpha$ DARC-P18F3, Nb- $\alpha$ DARC139 P18F4 were first subjected to surface plasmon resonance (SPR) analysis to determine their affinity 140 constants for their cognate molecular target, DARC. The extracellular domain of DARC (DARC141 ECD1) and the CA52 epitope-mutated form of this domain (DARC-ECD1-Mut), which is no 142 longer recognized by the anti-DARC nanobody (Supplementary Fig. 3), were expressed in E. coli 143 as fusion proteins with GST, purified (Fig. 2e) and then immobilized on the reference and 144 analytical channels ( $\mathrm{Fc} 1$ and Fc2, respectively) of a CM5 chip. Sensorgrams are shown in Figure 145 2f. The fitted kinetic data derived from the sensorgrams revealed that the fusion of P18-derived 146 polypeptides to $\mathrm{Nb}-\alpha \mathrm{DARC}$ did not modify the affinity ( $\mathrm{K}_{\mathrm{D}}$ constants ranging from $2.75 \mathrm{E}^{-11} \mathrm{M}$

147 to $\left.7.42 \mathrm{E}^{-11} \mathrm{M}\right)$ of the $\mathrm{Nb}$ binding moiety for its target as compared to $\mathrm{Nb}-\alpha \mathrm{DARC}$ alone $\left(\mathrm{K}_{\mathrm{D}}=9.00\right.$

$\left.148 \mathrm{E}^{-11} \mathrm{M}\right)\left(\right.$ Fig. 2f). Of note, the values of the $\mathrm{K}_{\text {off }}$ and $\mathrm{K}_{\text {on }}$ constants of Nb- $\alpha$ DARC-P18F2 markedly

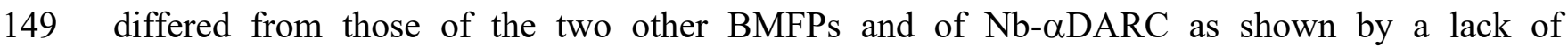
150 clusterization around $\mathrm{Nb}-\alpha \mathrm{DARC}$ in the RaPID plot shown in Fig. $\mathbf{2 g}$.

151 The capacity of the BMFPs to be bound by $\mathrm{IgG}$ present in the plasma of $\mathrm{EBV}^{+}$individuals was 152 then assessed. P18FL, that serves as a reference for IgG binding, was expressed in E. coli as a 153 maltose binding protein fusion (MBP-P18FL) to ensure appropriate solubility (Fig. $2 \mathbf{h}-$ left 154 panel). Enzyme-linked immunosorbent assay (ELISA) performed with 22 individual plasma 155 samples revealed that the binding of circulating IgG to Nb- $\alpha$ DARC-P18F2 and Nb- $\alpha$ DARC$156 \mathrm{P} 18 \mathrm{~F} 3$ were similar to the full-length P18, whereas binding to Nb- $\alpha \mathrm{DARC}-\mathrm{P} 18 \mathrm{~F} 4$ was much lower 157 (Fig. 2h - right panel). No binding to $\mathrm{Nb}-\alpha \mathrm{DARC}$ or to $\mathrm{MBP}$ was observed.

158 Overall, these results positioned $\mathrm{P} 18 \mathrm{~F} 3$ fused to the $\mathrm{Nb}-\alpha \mathrm{DARC}$ binding moiety as the shortest 159 P18-derived polypeptide bound by anti-P18 IgG to the same extent as the full-length P18, with no 
160 significant change in the specificity and affinity of the $\mathrm{Nb}-\alpha \mathrm{DARC}$ part of this BMFP for its

161 cognate target. $\mathrm{Nb}-\alpha \mathrm{DARC}-\mathrm{P} 18 \mathrm{~F} 3$ was therefore selected for further functional investigations.

163 Nb- $\alpha$ DARC-P18F3 binds to native DARC and recruits endogenous anti-EBV IgG to the 164 RBC surface.

165 The interaction of IgG present in human plasma pools, presenting different recognition levels for 166 the EBV-derived antigen P18F3, with Nb- $\alpha$ DARC-P18F3 bound to native DARC expressed at the 167 surface of DARC ${ }^{+}$RBCs (former genotype $\mathrm{FY}^{\mathrm{a}^{+}} / \mathrm{FY}^{\mathrm{b}+}$ ) was then assessed by flow cytometry (Fig.

168 3). An indirect anti-His-tag fluorescence assay showed first that the fusion of the P18F3 peptide 169 to the $\mathrm{C}$-terminus part of the $\mathrm{Nb}-\alpha \mathrm{DARC}$ did not prevent the resulting BMFP from binding to 170 RBCs, although a higher concentration was needed to reach the binding plateau as compared to

171 Nb- $\alpha$ DARC (Supplementary Fig. 4). Remarkably, in the presence of human plasma pools 172 exhibiting low, intermediate, and high antibody titers against P18F3, the binding of Nb- $\alpha$ DARC$173 \mathrm{P} 18 \mathrm{~F} 3$ to $\mathrm{DARC}^{+} \mathrm{RBC}$ led to the recruitment of anti-P18 IgG and hence to opsonization of the 174 target cells (Fig. 3a and Supplementary Fig. 5). The binding amplitude of IgG was in line with 175 the anti-P18F3 antibody titers found in the human plasma pools, as detected by an indirect 176 immunofluorescence assay (Fig. 3a). No noticeable recruitment of IgG was observed when RBCs

177 were incubated with $\mathrm{Nb}-\alpha \mathrm{DARC}$ regardless of the plasma pools tested. A qualitative analysis 178 performed by confocal microscopy confirmed that the fluorescence signal resulting from $\mathrm{Nb}$ $179 \alpha$ DARC-P18F3-mediated IgG recruitment was located at the cell surface of RBCs (Fig. 3b, c).

181 Nb- $\alpha$ DARC-P18F3-mediated RBC opsonization triggers erythrophagocytosis by 182 macrophage-like THP1 cells. 
183 Engagement of Fc $\gamma R I$ (CD64), Fc $\gamma$ RIIa (CD32a) and Fc $\gamma$ RIIIa (CD16a) present on monocytes and 184 macrophages promotes phagocytosis of IgG-opsonized target cells ${ }^{30}$. Thus, to assess if anti-P18F3 185 huIgG recruited by $\mathrm{Nb}-\alpha \mathrm{DARC}-\mathrm{P} 18 \mathrm{~F} 3$ bound to $\mathrm{DARC}^{+} \mathrm{RBC}$ were able to promote $\mathrm{RBC}$ 186 clearance by phagocytes, we performed an erythrophagocytosis assay using macrophage-like cells 187 derived from the monocytic leukemia THP1 cell line (CD64 $/$ CD32a $\left.{ }^{+} / \mathrm{CD} 16 \mathrm{a}^{-}\right)$(Supplementary 188 Fig. 6) ${ }^{31}$.

189 Carboxyfluorescein succimidyl ester (CFSE)-stained DARC ${ }^{+} \mathrm{RBC}$ sere incubated for $3 \mathrm{~h}$ at $37^{\circ} \mathrm{C}$ 190 with macrophage-like cells (obtained by PMA treatment of THP1 cells) in presence of Nb$191 \alpha$ DARC-P18F3 and of human plasma pools exhibiting low, intermediate, or high antibody titers 192 against P18F3. Flow cytometry analysis of macrophage-like THP1 cells revealed that the 193 percentage of $\mathrm{CFSE}^{+}$THP1 was largely increased when the cells were incubated with Nb- $\alpha$ DARC194 P18F3 and a human plasma pool exhibiting a high titer of anti-P18F3 antibodies (Fig. 4a). When $195 \mathrm{Nb}-\alpha \mathrm{DARC}$ was used instead of $\mathrm{Nb}-\alpha \mathrm{DARC}-\mathrm{P} 18 \mathrm{~F} 3$, no significant increase was observed (Fig. 196 4a). Four independent experiments confirmed that exposure of RBCs to Nb- $\alpha$ DARC-P18F3 and 197 human plasma pools containing high or intermediate antibody titers against P18, provokes an 198 increased erythrophagocytosis by THP1-derived macrophage-like cells (mean fold change 6.3 and 199 2.6, respectively) as compared to the condition using untreated RBCs (Fig. 4b). No increase was 200 observed in absence of plasma in the assay where Nb- $\alpha$ DARC-P18F3 was used (Fig. 4b). Of note, 201 erythrophagocytosis was more pronounced in presence of the plasma pool exhibiting the highest 202 antibody titer against P18F3 (as compared to the "no plasma" condition; $\mathrm{p}=0.0286$ ). In contrast, $203 \mathrm{RBC}$ treatment with $\mathrm{Nb}-\alpha \mathrm{DARC}$ did not modify the level of erythrophagocytosis directly exerted 204 by macrophage-like THP1 cells, regardless of the plasma pools tested (Fig. $\mathbf{4 b}$ ). 
Altogether, these results identified P18F3 as the most efficient P18-derived polypeptide able to

206 recruit specific IgG onto the cell surface of target cells. Fusion of P18F3 to a nanobody-based

207 binding moiety (Nb- $\alpha$ DARC) did not alter the intrinsic functionality of the 2 modules and 208 demonstrated a good capability to engage Fc $\gamma$ Rs on THP1-derived macrophages making it possible 209 to recruit anti-P18 antibodies, present in human plasma, that trigger RBC phagocytosis.

211 Engineering a BMFP against human CD20.

212 We also developed a BMFP containing a scFv directed against huCD20 fused to the N-terminal 213 end of P18F3 to target Burkitt's lymphoma cells in vitro and huCD20-expressing tumor cells in an 214 in vivo mouse tumor model.

215 An anti-huCD20 scFv comprising the $\mathrm{V}_{\mathrm{H}}$ domain fused to the $\mathrm{V}_{\kappa}$ domain with a (GGGGS) 216 interdomain linker, derived from the mouse $\operatorname{IgG} 2 \mathrm{~b}, \kappa 2 \mathrm{H} 7$ monoclonal antibody ${ }^{32}$, was engineered 217 (Fig. 5a) and expressed alone $\left(\mathrm{scFv}_{2} \mathrm{H} 7\right)$ or in fusion with $\mathrm{P} 18 \mathrm{~F} 3\left(\mathrm{scFv}_{2} \mathrm{H} 7-\mathrm{P} 18 \mathrm{~F} 3\right)$ (Fig. 5b and 218 Supplementary Fig. 7). Both constructs included a 6xHistidine tag (6xHis tag) at the C-terminus. 219 The binding of the $\mathrm{scFv}_{2} \mathrm{H} 7$ and $\mathrm{scFv}_{2 \mathrm{H}}-\mathrm{P} 18 \mathrm{~F} 3$ to native huCD20 expressed at the surface of cells 220 from the Burkitt's lymphoma cell line RAJI (Supplementary Fig. 8a) was assessed by an indirect 221 anti-His-tag fluorescence assay and flow cytometry (Supplementary Fig. 8b). Both $\mathrm{scFv}_{2} \mathrm{H} 7$ and $222 \mathrm{scFv}_{2 \mathrm{H} 7}-\mathrm{P} 18 \mathrm{~F} 3$ bound to huCD20-expressing RAJI cells and a similar binding was observed when 223 used at an equimolar concentration of $0.48 \mu \mathrm{M}$. As already observed with $\mathrm{Nb}-\alpha \mathrm{DARC}$ and $\mathrm{Nb}-$ $224 \alpha$ DARC-P18F3 (Supplementary Fig. 4), a difference in the binding curves of the two molecules 225 was seen (Supplementary Fig. 8b). This may reflect a steric hindrance for the binding of the anti226 6xHis antibody to the recombinant molecules when $\mathrm{P} 18 \mathrm{~F} 3$ is fused at their C-terminus rather than 227 a change in the ability of BMFPs to bind the target molecules (DARC and huCD20). 
229 ScFv2H7-P18F3-mediated anti-P18 IgG opsonization of Burkitt's Lymphoma cells activates

230 antibody-dependent complement cascade and triggers Fc $\gamma$ RIIIa-mediated activation of

231 intracellular signaling pathways.

232 We then evaluated if the binding of $\mathrm{scFv}_{2} \mathrm{H} 7-\mathrm{P} 18 \mathrm{~F} 3$ to Burkitt's lymphoma cells induced the 233 activation of the complement cascade in presence of a pool of heat-inactivated human plasma 234 exhibiting a high titer of anti-P18F3 antibodies. This activation leads to the formation of the C5b-

2358 complex that binds to $\mathrm{C} 9$ to form the membrane attack complex (MAC), C5b-9. Incubation of 236 RAJI cells with $\mathrm{scFV}_{2 \mathrm{H} 7}-\mathrm{P} 18 \mathrm{~F} 3$ in the presence of plasma led to more $\mathrm{C} 5 \mathrm{~b}-8 / 9$ deposition than 237 when untreated cells or cells coated with $\mathrm{scFv}_{2 \mathrm{H} 7}$ were tested as shown by an increased detection 238 of C5b-8/9 using either rabbit anti-C5b-9 antibodies (Mann-Whitney test, $p=0.0286)($ Fig. 5c) or 239 a mouse anti-C5b-8/9 mAb (Supplementary Fig. 9a).

240 The Fc $\gamma$ region of immuno-complexed IgG can bind to Fc $\gamma$ RIIIa/CD16a expressed at the surface 241 of Natural Killer (NK) cells and trigger an intracellular signaling cascade leading to the release of 242 IFN- $\gamma$, TNF- $\alpha$ and of perforin and granzymes from cytotoxic granules. Thus, we examined if 243 scFv2H7-P18F3-mediated anti-P18 IgG opsonization of Burkitt's Lymphoma cells could provoke 244 the crosslinking of Fc $\gamma$ RIIIa, hence triggering a signalling cascade that ultimately leads to ADCC. 245 Jurkat cells stably expressing human FcyRIIIa-V158, that binds IgG1 more efficiently than 246 FcyRIIIa-F158, were used as effector cells to monitor cell activation. In this reporter assay, 247 FcyRIIIa engagement by immune-complexes transduces intracellular signals resulting in NFAT248 mediated luciferase activity, which represents a robust and valid downstream readout for ADCC 249 induction by IgG1 antibodies ${ }^{33}$. Thus, huCD20 $0^{+}$RAJI cells were first opsonized with scFv2H7-

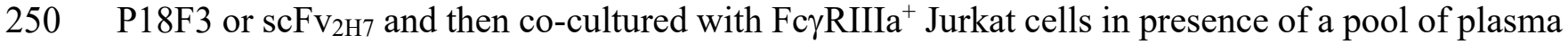


251 exhibiting a high titer of anti-P18F3 antibodies for $6 \mathrm{~h}$. Treatment of RAJI cells with $\mathrm{scFv}_{2 \mathrm{H}} \mathrm{F}^{-}$

252 P18F3 drastically increased NFAT-mediated luciferase activity in Jurkat cells in the presence of

253 plasma as compared to untreated cells or $\mathrm{scFv}_{2 \mathrm{H}}-$-coated cells (Fig. 5d and Supplementary Fig.

254 9b), demonstrating that P18F3-mediated anti-P18 IgG opsonization of Burkitt' Lymphoma cells

255 triggers Fc $\gamma$ RIIIa-mediated activation of intracellular signaling pathways that leads to ADCC.

257 Treatment with $\mathbf{s c F v}_{2 \mathrm{H} 7}-\mathrm{P} 18 \mathrm{F3}$ reduces cancer progression in mice bearing huCD20 ${ }^{+}$tumor 258 cells.

259 Firstly, in order to raise mouse antibodies directed against P18F3, $12 \mathrm{BALB} / \mathrm{cByJ}$ were immunized 260 with the P18FL protein fused to MBP (MBP-P18FL). Analysis of IgG subclasses 52 days after the 261 first injection revealed that around $46.8 \%$ of anti-P18F3 IgG are $\operatorname{IgG} 1$ and $34.9 \% \operatorname{IgG} 2 \mathrm{~b}$ (mean 262 values) (Supplementary Fig. 10). A smaller proportion of anti-P18 IgG belonged to the IgG3 and 263 IgG2a subclasses (10.4\% and 7.9\%, respectively) (mean values). Individual pre-immune and 264 immune sera from the 12 mice were then used to perform an opsonization assay with EL4-WT 265 cells and transduced EL4-huCD20 cells that stably express human CD20 ${ }^{34}$ (Supplementary Fig. 266 11a). In the presence of immune mouse sera, binding of $\mathrm{scFv}_{2 \mathrm{H} 7}-\mathrm{P} 18 \mathrm{~F} 3$ to EL4-huCD20 cells led

267 to the recruitment of anti-P18 mouse IgG as detected by an immunofluorescence assay using 268 specific goat anti-mouse IgG (Fc-specific) antibodies conjugated to allophycocyanine (APC) and 269 hence, to opsonization of target cells (Fig. 6a, right panel). No noticeable recruitment of IgG was 270 observed without $\mathrm{scFv}$ (Fig. 6a, left panel), when the $\mathrm{scFv}_{2 \mathrm{H}}$ was tested (Fig. 6a, middle panel) 271 and when EL4-WT were treated with $\mathrm{scFv}_{2 \mathrm{H} 7}$ or $\mathrm{scFv}_{2 \mathrm{H}}-\mathrm{P} 18 \mathrm{~F} 3$ and incubated with pre-immune 272 sera (Supplementary Fig. 11b, middle and right panels). 
273 Second, to determine whether or not $\mathrm{scFv}_{2 \mathrm{H} 7}-\mathrm{P} 18 \mathrm{~F} 3$ therapy can protect mice from tumor

274 challenge, C57B1/6 immunocompetent mice were immunized with MBP-P18FL to generate

275 endogenous anti-P18 antibodies (Fig. 6b). Mice were then injected intravenously with $2.5 \times 10^{5}$

276 EL4-huCD20 cells (Day 0) and received $\mathrm{scFv}_{2 \mathrm{H} 7}-\mathrm{P} 18 \mathrm{~F} 3$ therapy (group G1.1), consisting in four

277 intraperitoneal injections at days 1, 4, 7 and 10. In a first set of experiments, 3 additional control

278 groups $(\mathrm{n}=5)$ were injected with tumor cells. Mice from group G1.2 were left untreated, whereas

279 mice from group G1.3 received 4 injections of $\mathrm{scFv}_{2} \mathrm{H} 7$. Mice from group G1.4 received $\mathrm{scFv}_{2 \mathrm{H}}{ }^{-}$

280 P18F3 therapy but were not pre-immunized with MBP-P18FL (Fig. 6c). All mice from G1.2, G1.3

281 and G1.4 died within 35-50 days post tumor cell injection. In contrast, the overall long-term

282 survival in the G1.1 group ( $\mathrm{scFv}_{2} \mathrm{H} 7-\mathrm{P} 18 \mathrm{~F} 3$ therapy) was $40 \%$ (Fig. 6c). In a second set of

283 experiments involving a larger number of animals, 2 groups were designed. The G2.1 group ( $\mathrm{n}=11)$

284 did not receive any treatment after injection of tumor cells whereas the animals from the G2.2

285 group $(\mathrm{n}=12)$ received $\mathrm{scFv}_{2 \mathrm{H} 7}-\mathrm{P} 18 \mathrm{~F} 3$ therapy (Fig. 6d). All mice from the untreated group died

286 before Day 60 (median survival 35 days). $\mathrm{ScFv}_{2 \mathrm{H}}-\mathrm{P} 18 \mathrm{~F} 3$ therapy significantly increased mice

287 survival (median survival 51.5 days; Log-rank Mantel-Cox test, $\mathrm{p}=0.0387$ ) and led to an overall

288 17\% long-term survival. Two days before EL4-huCD20 cell injection, most of circulating anti-

289 P18F3 IgG in mice from G1.1 and G2.1 belonged to the IgG1 and IgG2b subclasses (Fig. 6c, 6d

290 - right panels) as already observed in sera from MBP-P18FL-immunized mice used to test IgG

291 opsonization (Supplementary Fig. 10). In addition, $\mathrm{scFv}_{2 \mathrm{H}}-\mathrm{P} 18 \mathrm{~F} 3$ treatment led to increased

292 levels of circulating antibodies directed against P18F3 at Day 15 post-treatment (Supplementary

293 Fig. 12).

294

295 DISCUSSION 
Here, we describe a strategy for re-directing a pre-existing EBV antibody response towards defined

297 pathogenic cells using bi-modular fusion proteins comprising a specific binding moiety and an

298 EBV-derived Ig recruiting antigen, P18. As a proof of concept, we first generated a set of BMFPs

299 targeting RBCs via an anti-DARC nanobody. Treatment of RBCs with BMFPs in presence of

300 human plasma from $\mathrm{EBV}^{+}$donors mediated target opsonization by circulating anti-P18 $\operatorname{IgG}$ and

301 the subsequent induction of erythrophagocytosis by macrophage-like cells. We then developed a

302 scFv-based BMFP directed towards huCD20 ( $\left.\mathrm{scFv}_{2 \mathrm{H}}-\mathrm{P} 18 \mathrm{~F} 3\right)$ and analysed its efficacy in vitro

303 and in vivo in a mouse tumour model. $\mathrm{ScFv}_{2 \mathrm{H} 7}-\mathrm{P} 18 \mathrm{~F} 3$-mediated opsonization of Burkitt's

304 lymphoma cells, activated the antibody-dependent cascade of the complement system and engaged

305 Fc $\gamma$ RIII in a cell assay recapitulating the first steps of ADCC triggering. When assessed in a tumour

306 model, $\mathrm{scFv}_{2 \mathrm{H} 7}-\mathrm{P} 18 \mathrm{~F} 3$ therapy significantly increased mice survival, leading to total cancer

307 remission in some animals.

308 The initial part of this work consisted in establishing that BMFPs, expressed in a bacteria-based 309 system, could be designed to efficiently target defined cellular elements. The conservation of the 310 intrinsic biochemical and functional properties of both modules ( $\mathrm{P} 18$ and binding moiety), is 311 crucial when designing BMFPs aiming at re-directing a pre-existing EBV antibody response

312 towards specific cells. In order to create a versatile therapeutic tool, in which the binding moiety

313 could be easily substituted, we first optimized the nature of the P18 antigen using a model targeting

314 DARC expressed at the surface of RBCs with a nanobody-based BMFP (Nb- $\alpha$ DARC). The EBV

315 antigen P18 has been selected primarily for its capability to be strongly bound by circulating IgG

316 from EBV-infected individuals ${ }^{18}$. Another important criterion for selecting P18 was the absence

317 of any post-translational addition of sugar moieties. P18 is a non-glycosylated protein of small size

$318(18 \mathrm{kDa})$ that could therefore be produced in a heterologous bacterial system. However, protein 
sequence analysis of $\mathrm{P} 18 \mathrm{FL}$ revealed that its $\mathrm{N}$-terminus part displays several stretches of

320 hydrophobic residues and numerous prolines that could potentially interfere with the expression

321 of stable proteins in physiological buffers. Furthermore, P18FL harbors a cysteine in position 56

322 that could unwillingly engage in disulfide bond formation with other cysteines present within the

323 binding moiety sequence during folding of the fusion constructs as antibody fragments possess

324 structuring disulfide-bonds mandatory for their functionality. To overcome these potential issues,

325 we designed P18 fragments lacking the N-terminus region that contains Cys56. In addition, we

326 used a mutant E. coli strain (SHuffle) that promotes disulfide bond formation in the cytoplasm,

327 leading to more efficient folding of recombinant proteins, improved activity and increased

328 production yields ${ }^{29}$. We also optimized the P18 antigen to efficiently recruit circulating anti-P18

$329 \mathrm{IgG}$, without affecting the functionality of the binding moiety. P18F3 was down-selected as the

330 prime P18-derived antigen, presenting binding titers by circulating anti-P18 IgG comparable to

331 that of P18FL, thus confirming the presence of immunodominant epitopes within the C-terminus

332 part of the protein ${ }^{35}$. Notably, fusion of P18F3 to $\mathrm{Nb}-\alpha \mathrm{DARC}$ did not significantly affect the

333 affinity of the $\mathrm{Nb}$ for its cognate target, DARC. Furthermore, RBC treatment with Nb- $\alpha$ DARC-

334 P18F3 triggered erythrophagocytosis by THP1-derived macrophages. The amplitude of

335 erythrophagocytosis correlated with the P18F3-binding titers of the circulating IgG, strongly

336 suggesting that erythrophagocytosis was driven by $\operatorname{IgG}$ opsonization rather than by pattern

337 recognition receptors or mannose receptor engagement.

338 Based on these results, we then generated a P18F3-derived BMFP comprising a scFv binding 339 moiety targeting huCD20 that is expressed at the surface of B lymphocytes from early 340 developmental stages (late pro-B cell) to late stages (memory B cell) as well as in most non341 Hodgkin's B lymphomas. MAb therapy targeting huCD20 has revolutionized the treatment of B- 
342 cell malignancies for more than 30 years, becoming the leading therapeutic agents for the care of

343 numerous B cell-related cancers such as follicular lymphoma, diffuse large B-cell lymphoma, 344 mantle cell lymphoma as well as Burkitt's lymphoma ${ }^{36}$. The most striking example of such success

345 is rituximab ${ }^{37}$. Several other therapeutic anti-huCD20 mAbs such as ofatumumab, obinutuzumab, 346 and ublituximab (derived from the EMAB-6 antibody ${ }^{38}$ ) have been developed since the advent of 347 rituximab (with alternate binding epitopes, additional humanization and modified 348 glycosylations) $)^{39,40}$. We have developed herein a binding moiety targeting the large extracellular 349 loop of huCD20 based on the $\mathrm{C} 2 \mathrm{H} 7$ (2H7) chimeric antibody, which presents a different binding 350 epitope profile than rituximab ${ }^{41}$. $\mathrm{ScFV}_{2 \mathrm{H} 7}-\mathrm{P} 18 \mathrm{~F} 3$ expression in SHuffle resulted in the production 351 of a soluble protein, with a production yield reaching $0.7-1 \mathrm{mg} \mathrm{ml}^{-1}$ of bacteria culture, in line with 352 previous work highlighting the difficulty to express stable and soluble scFv molecules ${ }^{42,43}$. We 353 demonstrate here that treatment of Burkitt's lymphoma cells with scFv2 2 7-P18F3, in the presence 354 of plasma from $\mathrm{EBV}^{+}$donors, activates the complement cascade leading to the formation of the 355 MAC as shown by the detection of C5b-9 deposition at the cell surface. The ability of the scFv2 $\mathrm{H}_{7-}$ $356 \mathrm{P} 18 \mathrm{~F} 3$ to trigger the MAC formation and deposit on target cells strongly supports the relevance of 357 BMFP-based treatments to deplete pathologic cells. Several in vivo studies have highlighted that 358 complement activation is important for the therapeutic activity of depleting antibodies, as 359 exemplified by anti-huCD20 $\mathrm{mAbs}^{34,44}$. Importantly, in addition to complement activation, $360 \mathrm{scFv}_{2 \mathrm{H} 7}-\mathrm{P} 18 \mathrm{~F} 3$-mediated opsonization also provoked the engagement of FcyRIII at the surface of 361 engineered Jurkat cells in presence of plasma from $\mathrm{EBV}^{+}$individuals, triggering the first steps of 362 the signaling cascade leading to ADCC. Thus, these data indicate that anti-huCD20 BMFPs used 363 in $\mathrm{EBV}^{+}$patients could enable the recruitment of endogenous anti-P18 $\mathrm{IgG}$ at the surface of 364 huCD20 ${ }^{+} \mathrm{B}$ cells, leading to the triggering of immune effector mechanisms. The continuous 
365 bioavailability of endogenous polyclonal $\operatorname{IgG}$ could represent a strong benefit to improve 366 engagement of the $\mathrm{C} 1 \mathrm{q}$ complement component and of $\mathrm{Fc} \gamma \mathrm{Rs}$, thus leading to a sustained 367 therapeutic efficacy. The in vivo anti-tumor efficacy of $\mathrm{scFv}_{2 \mathrm{H} 7}-\mathrm{P} 18 \mathrm{~F} 3$ therapy was therefore 368 assessed in a mouse model. Early attempts in the late seventies to develop in vivo EBV models by 369 virus inoculation of non-human primates did not result in asymptomatic persistent infections ${ }^{45}$.

370 Since then, humanized mice, which can recapitulate key aspects of EBV infection observed in 371 humans have been established ${ }^{46,47}$. However, these models are arduous to implement and still face 372 some severe limitations including sub-optimal $\operatorname{IgG}$ responses ${ }^{48}$. To assess the anti-tumor activity 373 of $\mathrm{scFv}_{2 \mathrm{H} 7}-\mathrm{P} 18 \mathrm{~F} 3$ in vivo in presence of anti-P18 antibodies, we used a mouse tumor model, in 374 which cells expressing human CD20 (EL4-huCD20) served as tumor target cells ${ }^{25,26,44,49}$. Mice 375 were first pre-immunized with MBP-P18FL to generate circulating anti-P18F3 antibodies. 376 Following EL4-huCD20 injection, preimmunized mice who received a $\mathrm{scFv}_{2} \mathrm{H} 7-\mathrm{P} 18 \mathrm{~F} 3$ therapy 377 showed a protection against tumor development as shown by an increased survival time and by 378 the full tumor clearance observed in $17 \%$ to $40 \%$ of the animals. Analysis of the mouse IgG 379 subclasses specific to P18F3 induced by MBP-P18FL immunization, revealed a predominance of 380 IgG1, and to a lower extent, of IgG2b. In contrast to human IgG1s, mouse IgG1s are poorly able 381 to bind $\mathrm{C} 1 \mathrm{q}$ or to engage activating Fc $\gamma$ Rs. Conversely, this subclass can efficiently bind to the 382 inhibitory Fc $\gamma$ RIIb. Thus, it is important to stress that despite these marked limitations, the efficacy 383 of $\mathrm{scFv}_{2 \mathrm{H}}-\mathrm{P} 18 \mathrm{~F} 3$ therapy, obtained after 4 injections of only $57 \mu \mathrm{g}$ of BMFP (per injection), is 384 achieved in less favorable conditions than in humans, where human IgG1, the major component 385 of the anti-P18 antibody response, exhibits strong effector functions through the binding to C1q 386 and activating FcyRs. Of note, the protection observed was obtained with a cumulative dose of $387228 \mu \mathrm{g}$ of the recombinant fusion BMFP, whereas previous work ${ }^{31,32,33}$, that used the same mouse 
388 tumor model, required a cumulative dose of $1 \mathrm{mg}$ of an IgG2a anti-huCD20 mouse mAb, the most

389 effective mouse subclass to engage $\mathrm{Fc} \gamma \mathrm{Rs}$ and to activate complement. Interestingly $\mathrm{scFv}_{2 \mathrm{H} 7}$ -

$390 \mathrm{P} 18 \mathrm{~F} 3$ treatment allowed the recall of the $\mathrm{P} 18 \mathrm{~F} 3$ antibody response, which could serve as a booster

391 in patients presenting low anti-P18F3 IgG titers.

393 Overall, EBV-derived bi-modular fusion proteins represent a versatile therapeutic tool for re394 directing an Epstein-Barr virus pre-existing antibody response towards defined target cells. Their 395 main advantages over the use of therapeutic depleting/cytotoxic mAbs are (i) the flexibility of the 396 constructs in terms of binding moieties that can be easily made of antibody fragments with various 397 specificities such as scFv, nanobodies or other types of ligands directed against a specific cell 398 surface receptor, ii) the lack of $\mathrm{Fc}$ region, rendering unnecessary any further $\mathrm{Fc}$ engineering for 399 gaining optimized effector functions due to the recruitment of polyclonal anti-P18 IgG1 exhibiting 400 excellent cytotoxic properties (CDC and ADCC), (iii) the reduced doses to be injected due to the 401 recruitment of polyclonal endogenous $\operatorname{IgG}$, mostly $\operatorname{IgG} 1$, directed against P18, a mechanism that 402 will amplify the efficacy of antibody-mediated effector functions, iv) a continuous bioavailability 403 of endogenous polyclonal effector IgG, v) the ability to produce large amounts of bi-modular 404 fusion proteins using bacteria and not eukaryotic cells, with reduced costs of production. 


\section{REFERENCES}

406 1. Lu, R.-M. et al. Development of therapeutic antibodies for the treatment of diseases. $J$. 407 Biomed. Sci. 27, 1 (2020).

408 2. Chiu, M. L., Goulet, D. R., Teplyakov, A. \& Gilliland, G. L. Antibody Structure and Function: 409 The Basis for Engineering Therapeutics. Antibodies. 8, (2019).

410 3. Kang, T. H. \& Jung, S. T. Boosting therapeutic potency of antibodies by taming Fc domain 411 functions. Exp. Mol. Med. 51, 1-9 (2019).

412 4. Wang, X., Mathieu, M. \& Brezski, R. J. IgG Fc engineering to modulate antibody effector 413 functions. Protein Cell 9, 63-73 (2018).

414 5. Gramer, M. J. et al. Modulation of antibody galactosylation through feeding of uridine, 415 manganese chloride, and galactose. Biotechnol. Bioeng. 108, 1591-1602 (2011).

416 6. Diebolder, C. A. et al. Complement is activated by IgG hexamers assembled at the cell surface. $417 \quad$ Science 343, 1260-1263 (2014).

418 7. Shields, R. L. et al. Lack of fucose on human IgG1 N-linked oligosaccharide improves binding 419 to human Fcgamma RIII and antibody-dependent cellular toxicity. J. Biol. Chem. 277, 26733$420 \quad 26740(2002)$.

421 8. Mimoto, F. et al. Novel asymmetrically engineered antibody Fc variant with superior Fc $\gamma \mathrm{R}$ 422 binding affinity and specificity compared with afucosylated Fc variant. $m A b s$ 5, 229-236 423 (2013).

424 9. Sibéril, S. et al. Selection of a human anti-RhD monoclonal antibody for therapeutic use: 425 impact of IgG glycosylation on activating and inhibitory Fc gamma R functions. Clin. $426 \quad$ Immunol. 118, 170-179 (2006). 
427 10. Beliard, R. et al. A human anti-D monoclonal antibody selected for enhanced FcgammaRIII 428 engagement clears $\mathrm{RhD}+$ autologous red cells in human volunteers as efficiently as polyclonal 429 anti-D antibodies. Br. J. Haematol. 141, 109-119 (2008).

430 11. Richards, J. O. et al. Optimization of antibody binding to FcgammaRIIa enhances macrophage 431 phagocytosis of tumor cells. Mol. Cancer Ther. 7, 2517-2527 (2008).

432 12. Dall'Acqua, W. F., Kiener, P. A. \& Wu, H. Properties of human IgG1s engineered for 433 enhanced binding to the neonatal Fc receptor (FcRn). J. Biol. Chem. 281, 23514-23524 (2006).

434 13. Robbie, G. J. et al. A novel investigational Fc-modified humanized monoclonal antibody, 435 motavizumab-YTE, has an extended half-life in healthy adults. Antimicrob. Agents $436 \quad$ Chemother. 57, 6147-6153 (2013).

437 14. Hendrikx, J. J. M. A. et al. Fixed Dosing of Monoclonal Antibodies in Oncology. The $438 \quad$ Oncologist 22, 1212-1221 (2017).

439 15. Young, L. S. \& Rickinson, A. B. Epstein-Barr virus: 40 years on. Nat. Rev. Cancer 4, $757-$ $440 \quad 768(2004)$.

441 16. Babcock, G. J., Decker, L. L., Volk, M. \& Thorley-Lawson, D. A. EBV persistence in memory 442 B cells in vivo. Immunity 9, 395-404 (1998).

443 17. Thorley-Lawson, D. A. EBV Persistence-Introducing the Virus. in Epstein Barr Virus 444 Volume 1 (ed. Münz, C.) vol. 390 151-209 (Springer International Publishing, 2015).

445 18. Ogolla, S. et al. Reduced Transplacental Transfer of a Subset of Epstein-Barr Virus-Specific 446 Antibodies to Neonates of Mothers Infected with Plasmodium falciparum Malaria during 447 Pregnancy. Clin. Vaccine Immunol. 22, 1197-1205 (2015).

448 19. Kaplon, H. \& Reichert, J. M. Antibodies to watch in 2021. mAbs 13, 1860476 (2021). 
20. Merle, N. S., Church, S. E., Fremeaux-Bacchi, V. \& Roumenina, L. T. Complement System

450 Part I - Molecular Mechanisms of Activation and Regulation. Front. Immunol. 6, 262 (2015).

451 21. Merle, N. S., Noe, R., Halbwachs-Mecarelli, L., Fremeaux-Bacchi, V. \& Roumenina, L. T.

452 Complement System Part II: Role in Immunity. Front. Immunol. 6, 257 (2015).

453 22. Nimmerjahn, F. \& Ravetch, J. V. Fc $\gamma$ receptors as regulators of immune responses. Nat. Rev.

$454 \quad$ Immunol. 8, 34-47 (2008).

455 23. Hogarth, P. M. \& Pietersz, G. A. Fc receptor-targeted therapies for the treatment of 456 inflammation, cancer and beyond. Nat. Rev. Drug Discov. 11, 311-331 (2012).

457 24. Anthony, R. M. et al. Recapitulation of IVIG anti-inflammatory activity with a recombinant $458 \quad$ IgG Fc. Science 320, 373-376 (2008).

459 25. Abès, R., Gélizé, E., Fridman, W. H. \& Teillaud, J.-L. Long-lasting antitumor protection by 460 anti-CD20 antibody through cellular immune response. Blood 116, 926-934 (2010).

461 26. DiLillo, D. J. \& Ravetch, J. V. Differential Fc-Receptor Engagement Drives an Anti-tumor $462 \quad$ Vaccinal Effect. Cell 161, 1035-1045 (2015).

463 27. Horuk, R. The Duffy Antigen Receptor for Chemokines DARC/ACKR1. Front. Immunol. 6, $464 \quad 279(2015)$

465 28. Smolarek, D. et al. A recombinant dromedary antibody fragment (VHH or nanobody) directed 466 against human Duffy antigen receptor for chemokines. Cell. Mol. Life Sci. CMLS 67, 3371$467 \quad 3387(2010)$.

468 29. Lobstein, J. et al. SHuffle, a novel Escherichia coli protein expression strain capable of 469 correctly folding disulfide bonded proteins in its cytoplasm. Microb. Cell Factories 11, 56 $470 \quad$ (2012). 
471 30. Uribe-Querol, E. \& Rosales, C. Phagocytosis: Our Current Understanding of a Universal

472 Biological Process. Front. Immunol. 11, 1066 (2020).

473 31. Tsuchiya, S. et al. Establishment and characterization of a human acute monocytic leukemia 474 cell line (THP-1). Int. J. Cancer 26, 171-176 (1980).

475 32. Liu, A. Y. et al. Production of a mouse-human chimeric monoclonal antibody to CD20 with 476 potent Fc-dependent biologic activity. J. Immunol. 1950 139, 3521-3526 (1987).

477 33. Parekh, B. S. et al. Development and validation of an antibody-dependent cell-mediated $478 \quad$ cytotoxicity-reporter gene assay. $m A b s \mathbf{4}, 310-318$ (2012).

479 34. Di Gaetano, N. et al. Complement activation determines the therapeutic activity of rituximab 480 in vivo. J. Immunol. 1950 171, 1581-1587 (2003).

481 35. van Grunsven, W. M., Spaan, W. J. \& Middeldorp, J. M. Localization and diagnostic 482 application of immunodominant domains of the BFRF3-encoded Epstein-Barr virus capsid 483 protein. J. Infect. Dis. 170, 13-19 (1994).

484 36. Casan, J. M. L., Wong, J., Northcott, M. J. \& Opat, S. Anti-CD20 monoclonal antibodies: 485 reviewing a revolution. Hum. Vaccines Immunother. 14, 2820-2841 (2018).

486 37. Salles, G. et al. Rituximab in B-Cell Hematologic Malignancies: A Review of 20 Years of 487 Clinical Experience. Adv. Ther. 34, 2232-2273 (2017).

488 38. de Romeuf, C. et al. Chronic lymphocytic leukaemia cells are efficiently killed by an anti489 CD20 monoclonal antibody selected for improved engagement of FcgammaRIIIA/CD16. Br. $490 \quad$ J. Haematol. 140, 635-643 (2008).

491 39. Soe, Z. N. \& Allsup, D. The use of ofatumumab in the treatment of B-cell malignancies. Future 492 Oncol. 13, 2611-2628 (2017). 
40. Prica, A. \& Crump, M. Improving CD20 antibody therapy: obinutuzumab in lymphoproliferative disorders. Leuk. Lymphoma 60, 573-582 (2019).

41. Du, J. et al. Crystal structure of chimeric antibody $\mathrm{C} 2 \mathrm{H} 7 \mathrm{Fab}$ in complex with a CD20 peptide. Mol. Immunol. 45, 2861-2868 (2008).

42. Wang, R. et al. Engineering production of functional scFv antibody in E. coli by co-expressing the molecule chaperone Skp. Front. Cell. Infect. Microbiol. 3, 72 (2013).

43. Sarker, A., Rathore, A. S. \& Gupta, R. D. Evaluation of $\mathrm{scFv}$ protein recovery from E. coli by in vitro refolding and mild solubilization process. Microb. Cell Factories 18, 5 (2019).

44. Golay, J. et al. The role of complement in the therapeutic activity of rituximab in a murine B lymphoma model homing in lymph nodes. Haematologica 91, 176-183 (2006).

45. Miller, G. et al. Lymphoma in cotton-top marmosets after inoculation with Epstein-Barr virus: tumor incidence, histologic spectrum antibody responses, demonstration of viral DNA, and characterization of viruses. J. Exp. Med. 145, 948-967 (1977).

46. Yajima, M. et al. A new humanized mouse model of Epstein-Barr virus infection that reproduces persistent infection, lymphoproliferative disorder, and cell-mediated and humoral immune responses. J. Infect. Dis. 198, 673-682 (2008).

47. Fujiwara, S., Imadome, K.-I. \& Takei, M. Modeling EBV infection and pathogenesis in newgeneration humanized mice. Exp. Mol. Med. 47, e135 (2015).

48. Akkina, R. New generation humanized mice for virus research: comparative aspects and future prospects. Virology 435, 14-28 (2013).

49. Deligne, C., Metidji, A., Fridman, W.-H. \& Teillaud, J.-L. Anti-CD20 therapy induces a memory Th1 response through the IFN- $\gamma /$ IL-12 axis and prevents protumor regulatory T-cell expansion in mice. Leukemia 29, 947-957 (2015). 


\section{ACKNOWLEDGMENTS}

518 This work was supported by a grant from the SATT IDF-Innov, Paris, France. Additional financial

519 support was provided by the Institut National de la Santé et de la Recherche Médicale (INSERM),

520 France and the Institut National de la Transfusion Sanguine (INTS), Paris, France. We are thankful

521 to Dr. Dominique Goossens, Dr. Zelia Gouveia, Ms Nathalie Josseaume for providing reagents, to 522 Mr Mickael Marin, Ms Sandy Peltier for technical assistance and to Dr. Geneviève Milon for 523 inspiring discussions.

524

525 AUTHOR CONTRIBUTIONS

526 BG, OB, SG, JLT, AC designed the research study. CB, NR, BKD, CEP, AD, JC, JPS, AC 527 performed the experiments and analyzed the data. BG, JLT, AC wrote the first version of the 528 manuscript. All authors critically reviewed and validated the submitted version of the manuscript.

\section{COMPETING INTERESTS}

$531 \mathrm{BG}, \mathrm{SG}$ and $\mathrm{AC}$ declare being listed as co-inventors of an international patent application 532 published under the patent cooperation treaty (PCT), WO2017/103020A1. The other authors 533 declare no competing interests.

\section{SUPPLEMENTARY INFORMATION}

536 Supplementary information accompanies this paper. 


\section{ONLINE METHODS}

\section{Production and purification of MBP-P18FL, DARC-ECD1 and DARC-Mut}

539 Genomic EBV DNA (strain B95-8) was isolated from cells of the marmoset (Callithrix jacchus)

540 cell line B95-8 (ECACC). The complete DNA sequences of the ORF BFRF3 encoding for the viral

541 capsid antigens P18 (UniProt P03197; aa 1-176) was cloned into the pMal-C2x plasmid (New

542 England Biolabs) suitable for expression of maltose-binding protein (MBP)-fusions. The

543 sequences coding for the extracellular domain of DARC (DARC-ECD1) and the CA52 epitope-

544 mutated form of this domain (DARC-ECD1-Mut), which is no longer recognized by the anti-

545 DARC nanobody (Supplementary Fig. 3), were cloned into the pGEX-5 plasmid (GE

546 Healthcare). For protein expression, BL21 competent E. coli (New England Biolabs) were

547 transformed with pMal-C2x-P18, the empty pMal-C2x plasmid (MBP alone), pGEX-5- DARC-

548 ECD1 as well as with pGEX-5-DARC-ECD1-Mut. Bacteria cultures were grown at $37^{\circ} \mathrm{C}$ until

$549 \mathrm{OD}_{600 \mathrm{~nm}} 0.5$ and protein expression was carried out for $3 \mathrm{~h}$ at $37^{\circ} \mathrm{C}$ with $0.1 \mathrm{mM}$ isopropyl $\beta$-d-1-

550 thiogalactopyranoside (IPTG) (Sigma). The bacteria pellets were resuspended in $50 \mathrm{mM}$ Tris, 500

$551 \mathrm{mM} \mathrm{NaCl}$ at $\mathrm{pH} 7.2$ and frozen at $-80^{\circ} \mathrm{C}$ until further use. For protein purification, bacteria

552 suspensions were thawed on ice and supplemented with ethylenediaminetetraacetic acid (EDTA)-

553 free cOmplete Protease Inhibitors (Roche) and with $1 \mathrm{mg} \mathrm{ml}^{-1}$ lysozyme from chicken egg white

554 (Sigma). Bacteria lysis was achieved by passing the cell suspensions through an EmulsiFlex-C5

555 high-pressure homogenizer (Avestin), three times at $4^{\circ} \mathrm{C}$. Following centrifugation at $12,000 \times \mathrm{x}$,

556 the supernatants containing soluble proteins were subjected to a 2-step purification process. MBP-

557 fusion proteins were first purified on Amylose resin (New England Biolabs) whereas GST-fusion

558 proteins were purified on glutathione sepharose 4 Fast Flow (GE healthcare) according to

559 manufacturer's instructions. Purified proteins were then passed through a Superdex 200 10/300 
560 GL gel filtration column (GE Healthcare) in phosphate-buffered saline (PBS) (Gibco) at pH 7.2.

561 Double-purified proteins were snap-frozen in liquid nitrogen and stored at $-80^{\circ} \mathrm{C}$.

562

\section{BMFPs cloning, expression and purification}

564 The DNA sequence ORF BFRF3 encoding for P18 was recoded and optimized for E. coli codon 565 usage (Integrated DNA Technology) to allow maximal expression in E. coli-based systems. The 566 full-length P18 (P18FL) recoded sequence as well as the truncated fragment (P18F2, P18F3, 567 P18F4) sequences were cloned into a pet28a-derived plasmid (Novagen) in order to express C568 terminus His-tagged proteins.

569 The anti-human $\mathrm{CD} 20$ (huCD20) $\mathrm{V}_{\mathrm{H}}$ and $\mathrm{V}_{\mathrm{K}}$ sequences of $\mathrm{scFv}_{2 \mathrm{H}}$ were obtained from the 570 sequences of an anti-human-CD28 $\mathrm{x}$ anti-huCD20 bispecific scFv antibody (clone r2820)

571 (Genebank AJ937362) and synthesized according to the following orientation: $\mathrm{V}_{\mathrm{H}}-(\mathrm{GGGGS})_{3}-\mathrm{V}_{\mathrm{K}}$.

572 The DNA sequences of $\mathrm{Nb}-\alpha \mathrm{DARC}$ and $\mathrm{scFv}_{2 \mathrm{H}}$ were inserted between the NheI and NcoI 573 restriction sites of Pet28a-NC (Supplementary Fig. 2). For each BMFP set, a construct 574 comprising the binding moiety but lacking P18 was also generated.

575 For protein expression, E. coli SHuffle (New England Biolabs) were transformed with the different 576 constructs. Bacteria cultures were induced with $0.2 \mathrm{mM}$ IPTG at $\mathrm{OD}_{600 \mathrm{~nm}} 0.8$ and protein 577 expression was carried out at $20^{\circ} \mathrm{C}$ for $16 \mathrm{~h}$. The bacteria pellets were resuspended in $50 \mathrm{mM}$ Tris, $578500 \mathrm{mM} \mathrm{NaCl}$ at $\mathrm{pH} 7.2$ and the samples were then frozen at $-80^{\circ} \mathrm{C}$ until further use. For protein 579 purification, bacteria suspensions were thawed on ice and supplemented with EDTA-free 580 cOmplete Protease Inhibitors (Roche) and with $1 \mathrm{mg} \mathrm{ml}^{-1}$ lysozyme from chicken egg white 581 (Sigma). Bacteria lysis was achieved by passing the cell suspensions through an EmulsiFlex-C5 582 high-pressure homogenizer (Avestin), three times at $4^{\circ} \mathrm{C}$. Following centrifugation at $12,000 \times \mathrm{g}$, 
583 the supernatants containing soluble proteins were subjected to a 2-step purification process. His-

584 tagged proteins were first purified on Ni-NTA Superflow columns (Qiagen) according to 585 manufacturer's instructions and then passed through a Superdex 200 10/300 GL gel filtration 586 column (GE Healthcare) in PBS at $\mathrm{pH}$ 7.2. Purified proteins were snap-frozen in liquid nitrogen 587 and stored at $-80^{\circ} \mathrm{C}$.

589 Blood samples. Whole blood samples were collected at the Etablissement Français du Sang (EFS)590 Cabanel, Paris, France (convention number CCPSLUNT-N²12/EFS/135). Red blood cells (RBCs) 591 and plasma samples were recovered after centrifugation of whole blood at $300 \times \mathrm{g}$ for $10 \mathrm{~min}$. 592 When required, complement inactivation was achieved by heating plasma samples at $56^{\circ} \mathrm{C}$ for 30 593 min. $\mathrm{DARC}^{+} \mathrm{RBC}$ from individuals with the $\mathrm{FY}^{\mathrm{a}} / \mathrm{FY}^{\mathrm{b}+}$ genotype were obtained from a reference 594 panel provided by the Centre National de Référence pour les Groupes Sanguins (CNRGS), Paris, 595 France.

597 Cell lines. The marmoset B95-8 cells that produce infectious EBV particles, the human 598 lymphoblastoid RAJI B cells (ECACC) and the human monocytic leukemia THP1 cells (ECACC) 599 were cultured in RPMI 1640 (Gibco), 2mM glutamine (Gibco), 10\% heat-inactivated Fetal Bovine 600 Serum (FBS) (Dominique Dutcher), penicillin-streptomycin $(100 \mathrm{U} / \mathrm{ml})$ at $37^{\circ} \mathrm{C}, 5 \% \mathrm{CO}_{2}$. EL4601 WT (ECACC) and EL4-huCD20 (kindly provided by Dr. J. Golay, Bergamo, Italy) cells were 602 maintained in DMEM (Gibco) supplemented with 2mM glutamine (Gibco), 20\% FBS, penicillin603 streptomycin $(100 \mathrm{U} / \mathrm{ml})$ at $37^{\circ} \mathrm{C}, 5 \% \mathrm{CO}_{2}$. 
606 DARC-ECD1. Interactions between the anti-DARC BMFPs and DARC were studied by surface

607 plasmon resonance (SPR), using a Biacore X100 instrument (GE Healthcare). All experiments 608 were performed in HBS-EP buffer (GE Healthcare) at $25^{\circ} \mathrm{C}$. For studying the binding of Nb$\alpha$ DARC, Nb- $\alpha$ DARC-P18F2, Nb- $\alpha$ DARC-P18F3, Nb- $\alpha$ DARC-P18F4 to DARC, DARC-ECD1

610 was immobilized on the analysis Fc2 channel of a CM5 chip (GE Healthcare) by amine coupling 611 whereas DARC-ECD1-Mut was immobilized on the reference channel Fc1. Both channels were 612 then blocked with $1 \mathrm{M}$ ethanolamine- $\mathrm{HCl} \mathrm{pH}$ 8.5. BMFPs were injected at $30 \mu \mathrm{min}^{-1}$ in dilution 613 series $(0.1$ to $125 \mu \mathrm{M})$ over the coated chips. Between the injections, the chip surface was 614 regenerated with 2 injections of $15 \mu \mathrm{l}$ of $10 \mathrm{mM} \mathrm{HCl} \mathrm{pH} \mathrm{2.0.} \mathrm{The} \mathrm{specific} \mathrm{binding} \mathrm{responses} \mathrm{to}$ 615 the molecular targets were obtained by subtracting the response given by the analytes on Fc2 with 616 the response on $\mathrm{Fc}$ 1. The kinetic sensorgrams were fitted to a global 1:1 interaction Langmuir 617 model and the $\mathrm{K}_{\text {off }}$ and $\mathrm{K}_{\text {on }}$ values were calculated using the manufacturer's software (Biacore 618 X100 Evaluation version 2.0).

Immune recognition of BMFPs by anti-P18 IgG-containing human plasma. Ultra-high

621 binding flat-bottom microtiter 96-well plates (Immulon 4HBX) were coated overnight at $4^{\circ} \mathrm{C}$ with $622100 \mu \mathrm{l}$ of anti-DARC or anti-huCD20 BMFPs at $1 \mu \mathrm{g} \mathrm{ml}^{-1}$ in PBS. Plates were then washed 3 623 times with $200 \mu 1$ PBS and blocked for $1 \mathrm{~h}$ at RT with $100 \mu 1$ of PBS $1 \%$ bovine serum albumin 624 (BSA) (Sigma). After blocking solution removing, three-fold serial dilutions $(1 / 2$ to $1 / 354,294)$ of 625 human plasma were added into the wells and incubated for $1 \mathrm{~h}$ at RT. Plates were then washed 626 three times with PBS. One hundred microliters of AffiniPure $\mathrm{F}\left(\mathrm{ab}^{\prime}\right)_{2}$ fragment donkey anti-human $627 \operatorname{IgG}(\mathrm{Fc} \gamma)$ Horseradish Peroxidase-conjugated antibody (Jackson Immunoresearch) diluted 1/4,000 
628 in PBS 1\% BSA were added to each well and incubated for $45 \mathrm{~min}$ at RT. Plates were then washed

629 three times with PBS and $100 \mu 1$ of TMB (3,3',5,5'-tetramethylbenzidine) substrate (Biorad) were

630 added per well. Absorbance was measured at $655 \mathrm{~nm}$ on an iMARK microplate absorbance reader

631 (Biorad). Data $\left(\mathrm{OD}_{655 \mathrm{~nm}}\right)$ were plotted and subjected to 4-parameter logistic regression curve 632 fitting.

634 Binding of BMFPs to native molecular targets. Target cells $\left(2.5 \times 10^{5}\right)$ (RBCs, RAJI cells, EL4-

635 WT, or EL4-huCD20 cells depending on the BMFPs tested) were distributed in a 96-well, round636 bottom, polystyrene microplate (Corning 3798) pre-coated with PBS 1\% BSA for $1 \mathrm{~h}$ at RT. To 637 prevent non-specific binding, cells were incubated with PBS $1 \%$ BSA for $1 \mathrm{~h}$ at $4^{\circ} \mathrm{C}$. Cells were 638 then pelleted by centrifugation at $300 \times \mathrm{g}$ for $3 \mathrm{~min}$ at $4^{\circ} \mathrm{C}$ and resuspended in $100 \mu \mathrm{l}$ of PBS $1 \%$ 639 BSA containing BMFPs at various concentrations. Following $1 \mathrm{~h}$ incubation at $4{ }^{\circ} \mathrm{C}$, cells were 640 washed three times with $200 \mu \mathrm{PBS} 1 \%$ BSA and resuspended in $100 \mu \mathrm{l}$ of PBS $1 \%$ BSA 641 containing $0.5 \mu \mathrm{g}$ of purified mouse anti-(H) (Penta-His) (Qiagen). After $45 \mathrm{~min}$, cells were 642 washed three times with $200 \mu \mathrm{PBS} 1 \%$ BSA and resuspended in $100 \mu$ of PBS $1 \%$ BSA 643 containing AffiniPure $\mathrm{F}\left(\mathrm{ab}^{\prime}\right)_{2}$ fragment goat anti-mouse IgG $(\mathrm{H}+\mathrm{L})$ PE-conjugated (1/100) 644 (Jackson Immunoresearch). After $45 \mathrm{~min}$, cells were washed three times with $200 \mu 1 \mathrm{PBS}$ and 645 subjected to flow cytometry analysis in the presence of TO-PRO ${ }^{\circledR}-3$ (Molecular probes) diluted 646 1/10,000. Data acquisition was performed using BD FACSCanto ${ }^{\mathrm{TM}}$ II flow cytometer (Becton647 Dickinson). Target cell gating was performed based on morphological features using the forward 648 (FSC) and side (SSC) scatters. TO-PRO ${ }^{\circledR}-3$ positive dead cells were excluded. Data were then 649 analyzed in FLOWJO 8.1 (Tree Star Inc.) software. 
651 Anti-DARC BMFPs-mediated opsonization of RBCs. Target cells $\left(2.5 \times 10^{5} \mathrm{RBCs}\right)$ were 652 distributed in a 96-well plate pre-coated with PBS 1\% BSA for $1 \mathrm{~h}$ at RT. To prevent non-specific 653 binding, RBCs were incubated with PBS $1 \%$ BSA for $1 \mathrm{~h}$ at $4^{\circ} \mathrm{C}$. Cells were then pelleted and 654 resuspended in $100 \mu \mathrm{l}$ of PBS 1\% BSA containing 9.6 nM Nb- $\alpha$ DARC-P18F3. Following $1 \mathrm{~h}$ 655 incubation at $4^{\circ} \mathrm{C}$, RBCs were washed three times with $200 \mu \mathrm{PBS} 1 \%$ BSA and resuspended in $656100 \mu \mathrm{l}$ of human plasma pools diluted from $1 / 5$ to $1 / 10,240$ in PBS $1 \%$. After $1 \mathrm{~h}$, cells were 657 washed three times with $200 \mu \mathrm{PBS} 1 \%$ BSA and resuspended in $100 \mu \mathrm{l}$ of PBS $1 \%$ BSA 658 containing AffiniPure $\mathrm{F}\left(\mathrm{ab}^{\prime}\right)_{2}$ fragment donkey anti-human IgG (Fc) PE-conjugated (1/100) 659 (Jackson Immunoresearch). After 45 min, RBCs were washed three times with $200 \mu$ PBS and 660 subjected to flow cytometry.

661

662 Antibody-dependent phagocytosis (ADP). THP1 cells were differentiated into M0 macrophage663 like cells with phorbol 12-myristate 13-acetate (PMA) (Sigma). Briefly, THP1 cells were seeded 664 in 12 -well plates $\left(7.5 \times 10^{5}\right.$ cells/well $)$ and incubated for $48 \mathrm{~h}$ at $37^{\circ} \mathrm{C}, 5 \% \mathrm{CO}_{2}$ in complete medium 665 supplemented with 20 ng/ml PMA. FY ${ }^{+}$human RBCs were stained with Carboxyfluorescein 666 succinimidyl ester (CFSE) (Thermo Fisher) according to manufacturer's instructions. Stained 667 RBCs were incubated for $1 \mathrm{~h}$ at RT with Nb- $\alpha$ DARC-18F3 or with $\mathrm{Nb}-\alpha \mathrm{DARC}$ at saturating 668 concentrations in PBS 1\% BSA and subsequently with human plasma pools diluted 1/10 in PBS $6691 \%$ BSA. Opsonized RBCs were then incubated for $3 \mathrm{~h}$ at $37^{\circ} \mathrm{C}, 5 \% \mathrm{CO}_{2}$ with $\mathrm{THP} 1$-derived 670 macrophages-like at an effector/target cell (E/T) ratio of 1/100. After co-incubation, non671 phagocytized RBCs were lysed with RBC lysis buffer (ChemCruz) and macrophages-like cells 672 were subjected to flow cytometry analysis in presence of TO-PRO ${ }^{\circledR}-3$ diluted $1 / 10,000$. CFSE $^{+}$ 673 macrophages-like cells were considered as cells having phagocytized at least one RBC. 
675 Activation of complement cascade. Target RAJI cells $\left(2.5 \times 10^{5}\right)$ were distributed in a 96-well 676 plate pre-coated with PBS 1\% BSA for $1 \mathrm{~h}$ at RT. To prevent non-specific binding, cells were 677 incubated with PBS $1 \%$ BSA for $1 \mathrm{~h}$ at $4^{\circ} \mathrm{C}$. Cells were then pelleted and resuspended in $100 \mu \mathrm{l}$ of 678 PBS $1 \%$ BSA containing $\mathrm{scFv}_{2 \mathrm{H} 7}-\mathrm{P} 18 \mathrm{~F} 3$ or $\mathrm{scFv}_{2 \mathrm{H} 7}$ at $0.48 \mu \mathrm{M}$. Following $1 \mathrm{~h}$ incubation at $4^{\circ} \mathrm{C}$, 679 cells were washed three times with $200 \mu$ PBS 1\% BSA and resuspended in $100 \mu$ l of undiluted 680 heat-inactivated $\left(56^{\circ} \mathrm{C}, 30 \mathrm{~min}\right)$ or untreated plasma. After a $1 \mathrm{~h}$ incubation at $37^{\circ} \mathrm{C}$, cells were 681 washed three times with $200 \mu \mathrm{PBS} 1 \%$ BSA and resuspended in $100 \mu \mathrm{l}$ of PBS $1 \%$ BSA 682 containing purified mouse $(\operatorname{IgG} 2 \mathrm{a}, \kappa)$ anti-C5b-9 $+\mathrm{C} 5 \mathrm{~b}-8[\mathrm{aE} 11]\left(20 \mu \mathrm{g} \mathrm{ml}^{-1}\right)$ or rabbit polyclonal 683 anti-C5b-9 $\left(25 \mu \mathrm{g} \mathrm{m}{ }^{-1}\right)($ Abcam $)$. After 45 min at $4^{\circ} \mathrm{C}$, cells were washed three times with 200 $684 \mu \mathrm{PBS} 1 \%$ BSA and resuspended in $100 \mu \mathrm{l}$ of PBS 1\% BSA containing APC-conjugated goat anti685 mouse IgG (Fc $\gamma$ fragment specific) (1/100) or PE-conjugated donkey anti-rabbit $\operatorname{IgG}(\mathrm{H}+\mathrm{L})$ 686 (1/100) (Jackson Immunoresearch). After 20 min at $4^{\circ} \mathrm{C}$, cells were washed three times with 200 $687 \mu \mathrm{PBS}$ and subjected to flow cytometry analysis.

689 Triggering of early events of Antibody-Dependent Cell-mediated Cytotoxicity (ADCC).

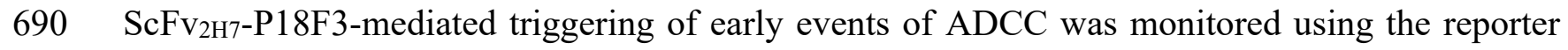
691 Bioassay Core Kit (Promega) according to manufacturer's instructions. Target RAJI cells $(12,500)$ 692 were distributed in a 96-well plate pre-coated with PBS 1\% BSA for $1 \mathrm{~h}$ at RT. To prevent non693 specific binding, cells were incubated with PBS 1\% BSA for $1 \mathrm{~h}$ at $4^{\circ} \mathrm{C}$. Cells were then pelleted 694 and resuspended in $100 \mu \mathrm{l}$ of PBS $1 \%$ BSA containing $\mathrm{scFv}_{2 \mathrm{H} 7}-\mathrm{P} 18 \mathrm{~F} 3$ or $\mathrm{scFv}_{2 \mathrm{H} 7}$ at $0.48 \mu \mathrm{M}$. 695 Following $1 \mathrm{~h}$ incubation at $4^{\circ} \mathrm{C}$, cells were washed three times with $200 \mu \mathrm{PBS} 1 \%$ BSA and 696 resuspended in ADCC Assay Buffer containing heat-inactivated $\left(56^{\circ} \mathrm{C}, 30 \mathrm{~min}\right)$ human plasma at 
697 different dilutions. Effector Fc $\gamma \mathrm{RIII}^{+}$Jurkat cells $(75,000)$ were added into each well. Plates were

698 incubated at $37^{\circ} \mathrm{C}, 5 \% \mathrm{CO}_{2}$ for $6 \mathrm{~h}$. Plates were then equilibrated at $25^{\circ} \mathrm{C}$ for $15 \mathrm{~min}$ before the

699 introduction of Bio-Glo ${ }^{\mathrm{TM}}$ into each well. Plates were left $30 \mathrm{~min}$ at $25^{\circ} \mathrm{C}$ before luminescence 700 reading on a PerkinElmer Victor 2030 plate reader.

702 Generation of mouse anti-P18FL antibodies. Six-week-old female BALB/cByJ mice (Charles 703 River) were immunized with MBP-P18FL following 4 subcutaneous injections at Days 0, 14, 28 704 and $42(25 \mu \mathrm{g}$ MBP-P18FL/injection in combination with complete Freund adjuvant (CFA) at Day 7050 and incomplete Freund adjuvant (IFA) at Days 14, 28 and 42). Blood samples were collected at 706 Day -1 (pre-immune serum) and at Day 52 (immune serum). Mice immunization was performed 707 by Biotem (Grenoble, France, ISO9001:2015; certificate FR0536014-1). Animal immunization 708 was executed in strict accordance with good animal practices, following the EU animal welfare 709 legislation and after approval of the INSERM and Biotem ethical committees.

711 Anti-CD20 BMFP-mediated opsonization of RAJI and EL4-huCD20 cells. RAJI or EL4712 huCD20 target cells $\left(2.5 \times 10^{5}\right)$ were distributed in a 96-well plate pre-coated with PBS $1 \%$ BSA

713 for $1 \mathrm{~h}$ at RT. To prevent non-specific binding, cells were incubated with PBS $1 \%$ BSA for $1 \mathrm{~h}$ at $7144^{\circ} \mathrm{C}$. Cells were then pelleted and resuspended in $100 \mu$ of PBS $1 \%$ BSA containing $0.48 \mu \mathrm{M}$ $715 \mathrm{scFv}_{2 \mathrm{H}}-\mathrm{P} 18 \mathrm{~F} 3$. Following $1 \mathrm{~h}$ incubation at $4^{\circ} \mathrm{C}$, cells were washed three times with $200 \mu \mathrm{PBS}$ $7161 \%$ BSA and resuspended in $100 \mu$ of individual mouse serum (diluted from $1 / 10$ ) in PBS $1 \%$.

717 After $1 \mathrm{~h}$, cells were washed three times with $200 \mu \mathrm{PBS}$ 1\% BSA and resuspended in $100 \mu \mathrm{l}$ of 718 PBS 1\% BSA containing AffiniPure $\mathrm{F}\left(\mathrm{ab}^{\prime}\right)_{2}$ fragment goat anti-mouse $\mathrm{IgG}(\mathrm{H}+\mathrm{L})$ PE-conjugated 719 (1/100) (Jackson Immunoresearch). After $45 \mathrm{~min}$, cells were washed three times with $200 \mu \mathrm{PBS}$ 
720 and subjected to flow cytometry analysis in the presence of TO-PRO ${ }^{\circledR}-3$ diluted $1 / 10,000$ to

721 discriminate live and dead cells.

722

723 In vivo tumor therapy. Six-week-old female immunocompetent $\mathrm{C} 57 \mathrm{Bl} / 6$ mice (Charles River)

724 were immunized with MBP-P18FL by 3 subcutaneous injections at Days 0,14 and $28(25 \mu \mathrm{g}$

725 MBP-P18FL/injection in combination with CFA at Day 0 and IFA at Days 14 and 28). Mice were

726 then intravenously inoculated in the tail vein on Day 0 with $2.5 \times 10^{5}$ EL4-huCD20 cells per mouse

727 (in $200 \mu \mathrm{L}$ PBS, pH 7.4), 56 days (experiment 1, Fig 6c) or 10 days (experiment 1, Fig 6d) after

728 the last immunization with MBP-P18FL. $\mathrm{ScFv}_{2 \mathrm{H} 7}-\mathrm{P} 18 \mathrm{~F} 3$ therapy was given as 4 intraperitoneal

729 injections of $57 \mu \mathrm{g}$ per mouse (in $200 \mu \mathrm{PBS}, \mathrm{pH}$ 7.4) on Days 1, 4, 7 and 10. Another group of

730 mice received $46 \mu \mathrm{g}$ of $\mathrm{scFv}_{2 \mathrm{H} 7}$ (in $200 \mu \mathrm{lBS}, \mathrm{pH}$ 7.4) according to the same injection schedules.

731 Animals were followed daily for up to 120 days. Mice were euthanized as soon as one of the

732 following clinical criteria appeared: presence of tumor on palpation, hindquarter paralysis,

733 prostration, weight loss, hair bristling, abnormal abdominal swelling. Blood samples were

734 collected 2 days before and 15 days after the start of the treatment. Animal experimentation was

735 performed in compliance with guidelines from the European Union (EU guideline on animal

736 experiments, European Directive \#2010/63/ EU) and the national charter on ethics in animal

737 experiments and was approved by the local Charles Darwin Ethics Committee in Animal

738 Experiments, Paris, France (Authorization Number 01530.02).

740 Analysis of anti-scFv $2 \mathbf{v}_{27}-\mathbf{P 1 8 F 3}$ IgG subclasses. Ultra-high binding flat bottom microtiter 96-

741 well plates (Immulon 4HBX) were coated overnight at $4^{\circ} \mathrm{C}$ with $100 \mu 1$ of $\mathrm{scFv}_{2 \mathrm{H}}-\mathrm{P} 18 \mathrm{~F} 3$ at 1

$742 \mu \mathrm{g} / \mathrm{ml}$ in PBS. Plates were then washed 3 times with $200 \mu \mathrm{PBS}$ and blocked for $1 \mathrm{~h}$ at RT with 
$743100 \mu 1$ of PBS 1\% bovine serum albumin (BSA) (Sigma). After blocking removing solution, 744 individual mouse sera (1/5) in PBS 1\% BSA were added into the wells and incubated for $1 \mathrm{~h}$ at

745 RT. Plates were then washed three times with PBS. One hundred microliters of goat anti-mouse

746 IgG1, IgG2a, IgG2b or IgG3 Alkaline Phosphatase (AP)-conjugated (Jackson Immunoresearch)

747 diluted 1/4,000 in PBS 1\% BSA were added to each well and incubated for 45 min at RT. Plates

748 were then washed three times with PBS and $100 \mu 1$ of TMB (3,3',5,5'-tetramethylbenzidine)

749 substrate (Biorad) were added per well. Absorbance was measured at $415 \mathrm{~nm}$ on an iMARK

750 microplate absorbance reader (Biorad).

751

752 Antibodies. All antibodies used in the study are listed in Supplementary Table 1.

\section{REPORTING SUMMARY}

755 Further information on research design is available in the Nature Research Reporting Summary 756 provided with the manuscript.

\section{DATA AVAILABILITY}

759 The data supporting the findings of this study are available within the manuscript and/or its 760 supplementary materials. Any addition information could be provided upon request. 


\section{Figures}

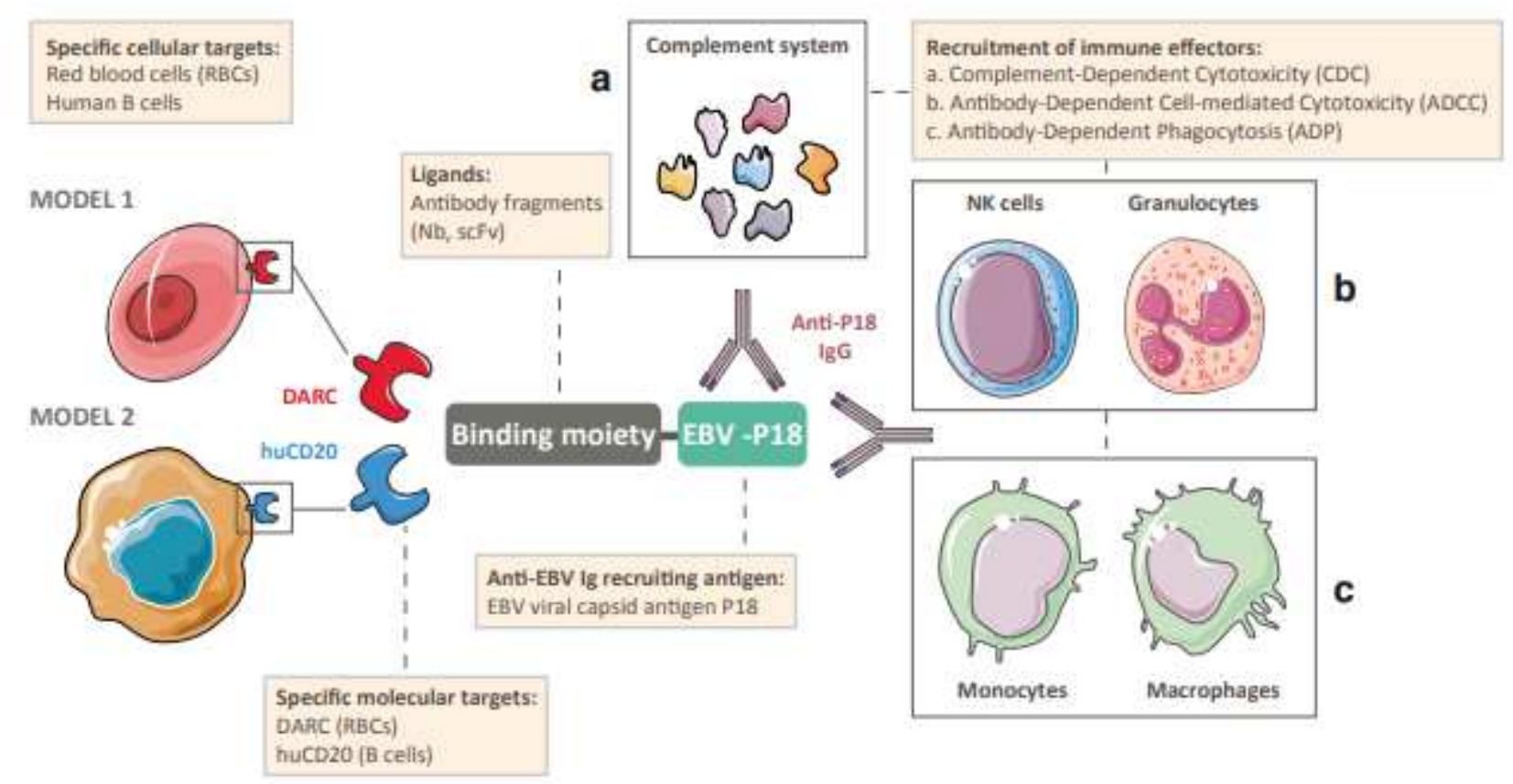

Figure 1

Conceptual modes of action of bi-modular fusion proteins (BMFPs). The EBV-P18 antigen is bound by circulating anti-EBV IgG present in the plasma of individuals chronically infected by EBV. Once fused to a binding moiety specifically directed to a molecule expressed by the targeted cells, P18 can serve as a recruiting agent for endogenous anti-P18 IgG and mediate their opsonization. The subsequent triggering of antibody-dependent effector mechanisms, i.e., complement activation via Fcy binding to the complement component C1q (a) and/or ADCC and phagocytosis by immune cells expressing Fcy receptors $(b, c)$ ultimately leads to the elimination of the target cells. Target cells and relevant target molecules developed in the two models assessed in this study are depicted. Nb: Nanobody. ScFv: Singlechain Fragment variable. DARC: Duffy Antigen Receptor for Chemokines. huCD20: human Cluster of Differentiation 20. The art pieces used in the figure were obtained from Servier Medical Art by Servier, licensed under a Creative Commons Attribution 3.0 Unported License (https://smart.servier.com/) and modified. 


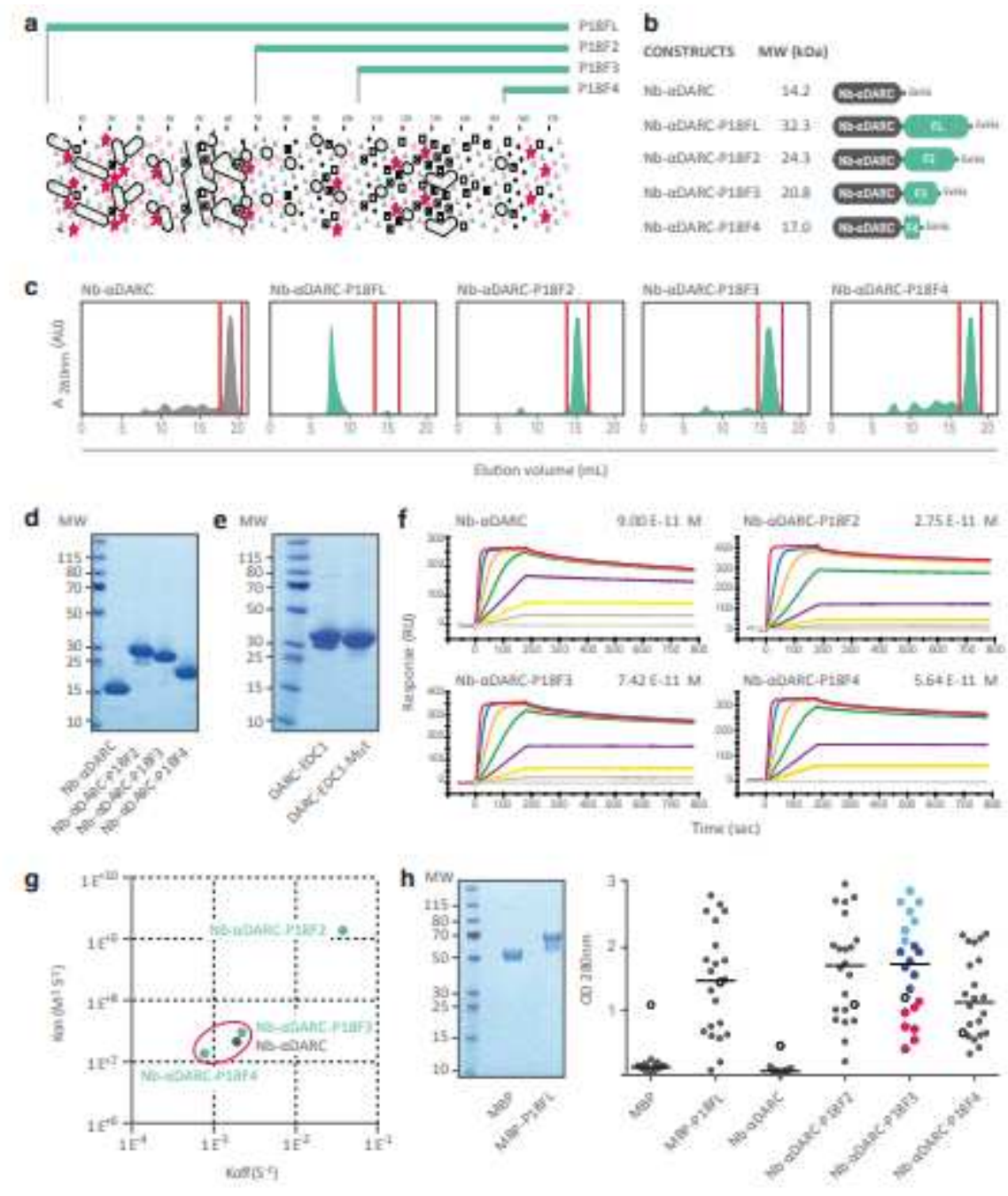

Figure 2

Engineering bi-modular fusion proteins (BMFPs) against DARC. (a) Hydrophobic cluster analysis plot of P18 (EBV strain B95-8). Strong hydrophobic amino acids are encircled, and their contours are joined, forming clusters. Analysis performed with HCA 1.0.2 (Ressource Parisienne en Biolnformatique Structurale). Three P18-derived fragments (P18F2, P18F3, P18F4) have been designed with regard to their limited content in hydrophobic clusters. (b) Architecture of BMFPs comprising a nanobody (Nb) targeting the Duffy Antigen Receptor for Chemokines (DARC) and P18 fragments of different lengths. MW: Molecular weight. (c) Gel filtration profiles of Nb-aDARC and Nb-DARC-P18 BMFPs. For each sample, red bars delimit the protein of interest (POI) pick. AU: Arbitrary Units. (d) Purity of eluted POI was assessed by SDS-PAGE followed by Coomassie blue staining. (e) Following expression and purification, the purity of the GST fusion proteins DARC-ECD1 and DARC-ECD1-Mut (lacking the CA52 epitope) was assessed by SDS-PAGE followed by Coomassie blue staining. (f) Sensorgrams resulting from surface plasmon resonance analysis of the interactions between immobilized DARC and aDARC-P18 BMFPs. Nb-aDARC was included as a reference protein. Calculated KD values are displayed for each construct. RU: Response Units. M: molar. (g) RaPID plot resulting from SPR analysis of the interactions between DARC-EDC1 and the Nb-aDARC-P18 BMFPs. Calculated Kon and Koff values were plotted for each protein including NbaDARC. Both Nb-aDARC-P18F3 and Nb-aDARC-P18F4 cluster around Nb-aDARC within the red circle. (h) 
Left panel. Following expression and purification, the purity of the MBP-P18FL fusion protein and of MBP alone was assessed by SDS-PAGE followed by Coomassie blue staining. Right panel. ELISA results of the binding of IgG present in plasma samples from 22 EBV+ individuals (1:100 dilution) to aDARC-P18 BMFPs. The full-length P18 polypeptide was included in the assay (MBP-P18FL). OD: Optical Density. MBP: Maltose-Binding Protein. Seven plasma samples displaying low, mild or high binding levels to $\mathrm{Nb}$ aDARC-P18F3 (red, dark blue and light blue dots, respectively) were mixed together to obtained 3 different plasma pools (low, mild, high) to be used in further experiments (Fig. 3). The plasma sample recognizing both MBP (white dot) and Nb-aDARC alone (white dot) was excluded from pooling.
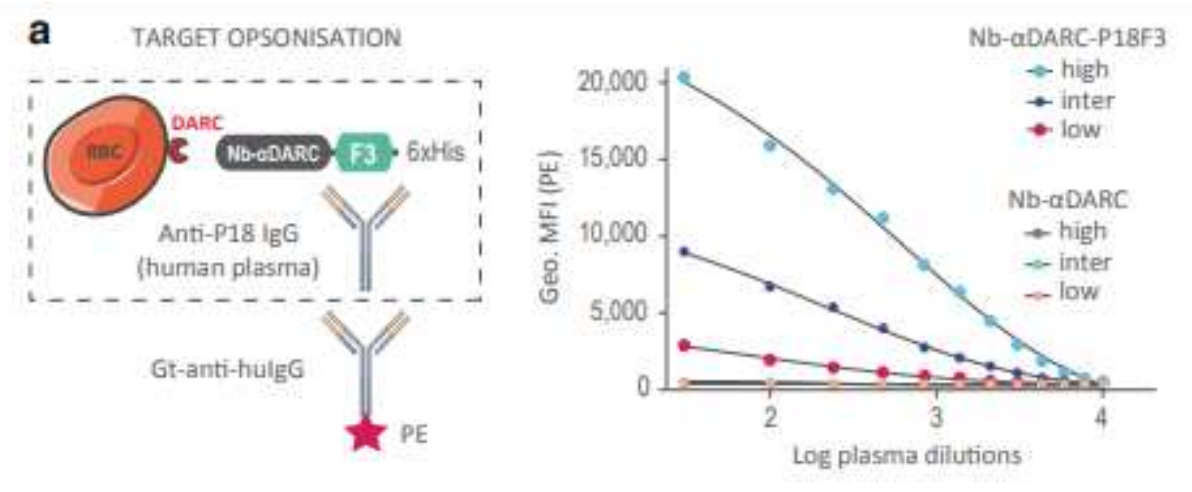

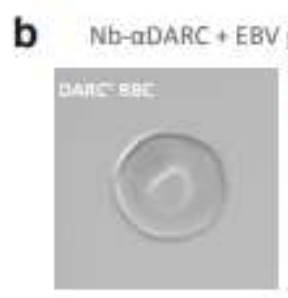

Bright light

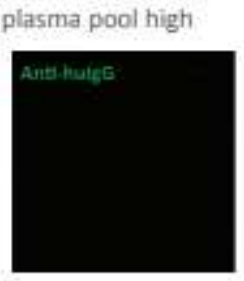

AF488

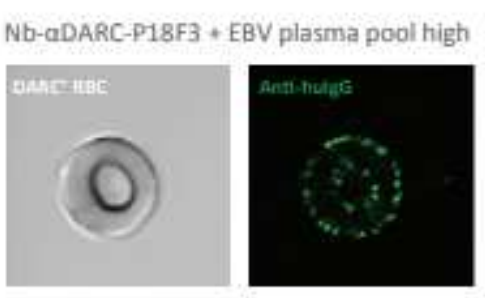

Bright light

AF- 488

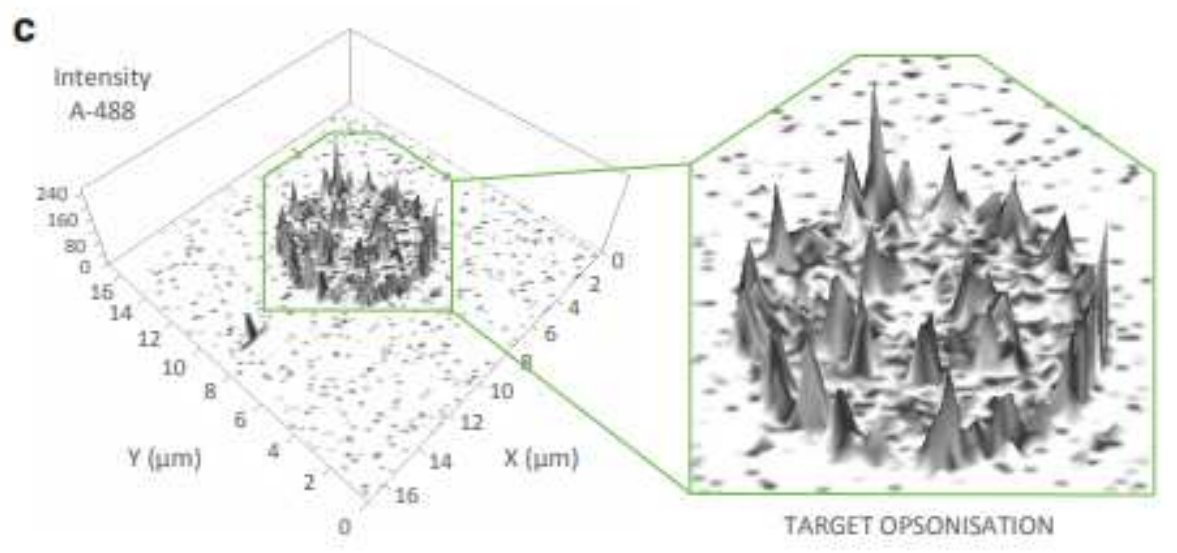

\section{Figure 3}

$\mathrm{Nb}-\mathrm{aDARC}-\mathrm{P} 18 \mathrm{~F} 3$ binds to native DARC and recruits anti EBV-human IgG (hulgG) to the RBC surface promoting target opsonisation. (a) The ability of Nb-aDARC-P18F3 to promote RBC opsonization by IgG present in the human plasma pools exhibiting different antibody titers against P18F3 was assessed by an indirect immunofluorescence assay and flow cytometry. Nb-aDARC and Nb-a DARC-P18F3 were used at a concentration that results in a similar binding to RBCs, $9.6 \mathrm{nM}$ (Supplementary Fig 4). Membrane bound hulgG were detected using anti-hulgG antibodies conjugated to phycoerythrin (PE). Plotted data 
represent the mean values of duplicates. (b) A qualitative analysis was performed by confocal microscopy to confirm that the signal resulting from hulgG detection was localized at the RBC surface. Upper panels. Confocal laser scanning microscopy images of hulgG distribution on the RBC membrane after incubation of RBCs with Nb-aDARC or Nb-a DARC-P18F3 in presence of plasma exhibiting a high antibody titer to $\mathrm{P} 18 \mathrm{~F} 3$. The binding of hulgG was revealed with goat Alexa Fluor-488-anti-hulgG antibodies (indicated as A-488). (c) 2.5D representation of the A-488 signal obtained when RBCs were incubated with Nb-a DARC-P18F3 in presence of plasma exhibiting a high antibody titer to P18F3. The right inset shows the enlarged 2.5D representation. Fluorescence is located at the RBC surface. Due to the biconcave shape of RBCs, membrane fluorescence located within the cell structure on the scanning microscopy images must not be mistakenly interpretated as cytosolic fluorescence. Confocal microscopy was performed with a Zeiss LSM700 microscope and images were analyzed with ZEN 2.0 software. AF488: Alexa 488.
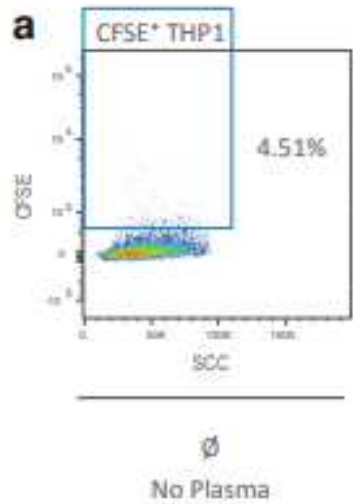
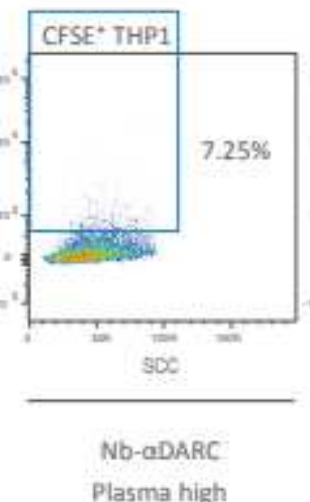

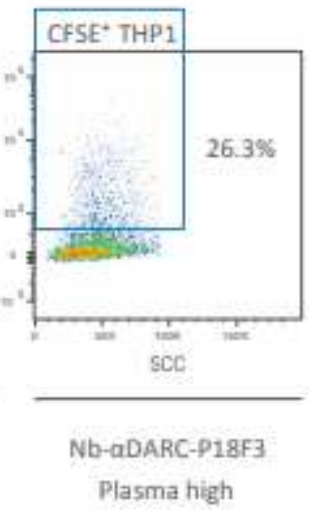

Plasma high

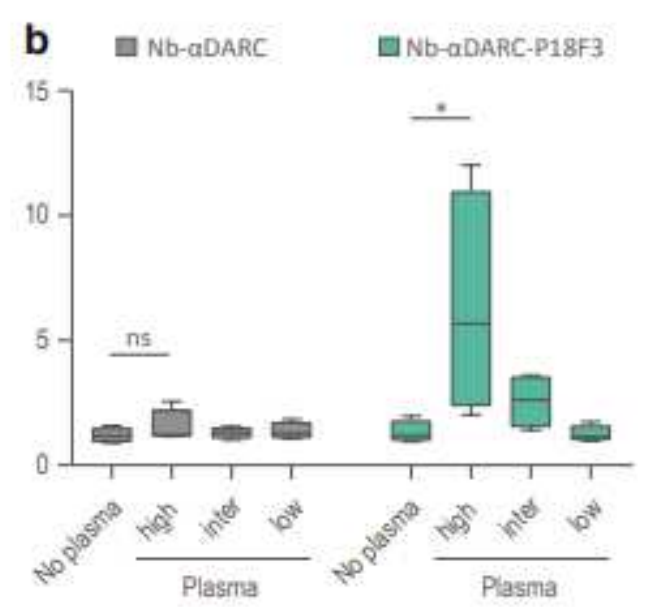

\section{Figure 4}

Nb-aDARC-P18F3-mediated hulgG RBC opsonization triggers erythrophagocytosis by macrophage-like THP1 cells. The ability of Nb-aDARC-P18F3 to promote RBC phagocytosis by THP1-derived macrophages was assessed in an erythrophagocytosis assay. CFSE-stained DARC+ RBCs were first incubated with NbaDARC or Nb-aDARC-P18F3 and with plasma pools exhibiting different antibody titers against P18F3. Following a 3h culture with THP1-derived macrophages, non-phagocytized RBCs were lysed and THP1 cells were then subjected to immunofluorescence analysis. (a) Representative data obtained from one experiment. A CFSE+ THP1 cell was regarded as a cell having phagocytized at least one RBC. Untreated cells (left panel) served as a reference for basal erythrophagocytosis by macrophage-like THP1-derived cells. Nb-aDARC-P18F3 treatment of RBCs in presence of plasma exhibiting a high antibody titer against P18 (indicated plasma high) led to a marked increase in the percentage of CFSE+ THP1 cells (right panel) as compared to Nb-aDARC-treated RBCs (middle panel). CFSE+ THP1 represents CFSE+ macrophage-like THP1-derived cells. SCC, Side SCatter. (b) Results obtained from 4 independent experiments are expressed as a fold increase (ordinate) in the percentage of CFSE+ macrophage-like THP1-derived cells incubated with RBCs coated with Nb-aDARC or Nb-aDARC-P18F3 and plasma pools exhibiting different 
antibody titers against P18F3 (high, intermediate, low) compared to the percentage of CFSE+ cells incubated with untreated RBCs (i.e., no incubation with Nb-aDARC or Nb-aDARC-P18F3 and no plasma). Box plots include the mean horizontal line and interquartile range (box), whereas the whiskers represent the minimal and maximal values. Group comparison was performed using the non-parametric MannWhitney test. P-values $<0.05$ were regarded as statistically significant $\left({ }^{*}\right)$. ns: non significant. Inter : intermediate.
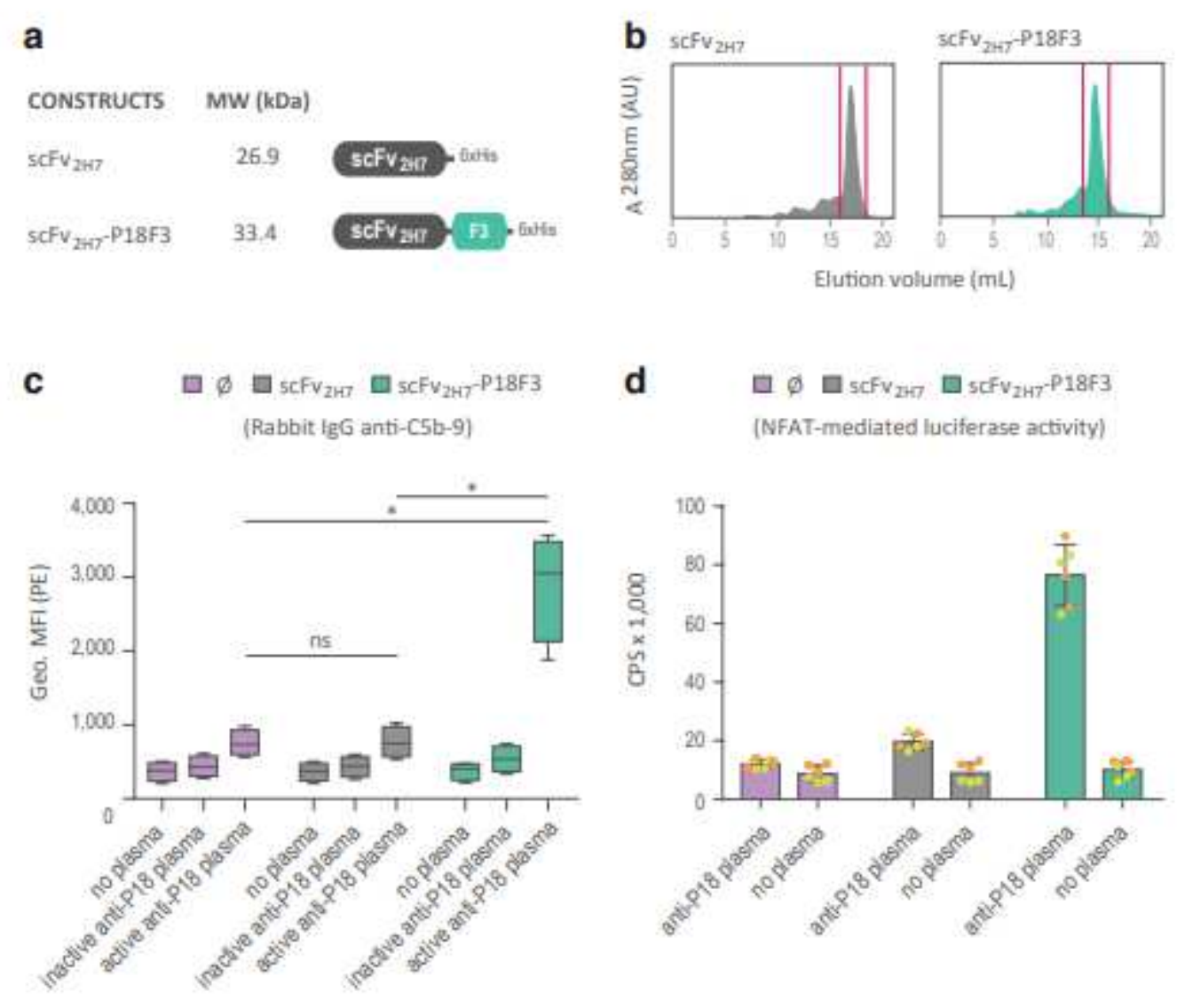

\section{Figure 5}

ScFv2H7-P18F3-mediated opsonization of Burkitt's Lymphoma cells induces activation of the antibodydependent complement cascade and triggers FcyRllla-mediated activation of intracellular signaling pathways that leads to ADCC. (a) Architecture of BMFP (scFv2H7-P18F3) and of scFv2H7 targeting huCD20. MW: Molecular weight. (b) Gel filtration profiles of scFv2H7 and scFv2H7-P18F3. For each elution, red bars delimit the protein of interest (POI) pick. AU: Arbitrary Units. (c) The capability of scFv2H7-P18F3 to promote complement activation through the classical pathway (antibody-dependent) was assessed by monitoring the deposition of the membrane attack complex (MAC) C5b-9 at the surface of RAJI cells. RAJI cells were incubated with saturating concentration of scFv2H7 or scFv2H7-P18F3 and with a pool of human plasma exhibiting a high titer of anti-P18 antibodies. Ø: no scFv protein. Results obtained from 4 independent experiments are depicted. Box plots include the mean horizontal line and interquartile range (box), whereas the whiskers represent the minimal and maximal values. Group comparison was performed using the non-parametric Mann-Whitney test. P-values $<0.05$ were regarded 
as statistically significant $\left({ }^{\star}\right)$. ns: non-statistically significant. (d) The capability of scFv2H7-P18F3 to promote the early events that lead to ADCC was assessed using a reporter assay. Activation of gene transcription through the NFAT pathway in competent effector Jurkat cells was quantified using a luciferase assay. RAJI cells were incubated with saturating concentration of scFv2H7 or scFv2H7-P18F3 and with a pool of human plasma exhibiting a high titer of anti-P18 antibodies and put in presence of Jurkat cells expressing human FcyRIlla-V158 (ratio: 1:6) for $6 \mathrm{~h}$. NFAT pathway activation was monitored by reading the luminescence of each plate well. CPS: counts per second. Ø: no scFv protein. Results obtained from 2 independent experiments performed in triplicates are depicted (exp.1, exp.2 ). Boxes represent the mean values of the six measurements and the error bars depict the associated standard deviations.
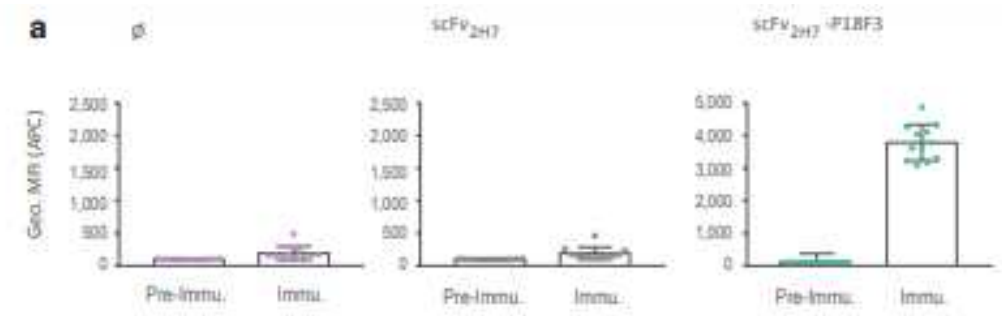

b
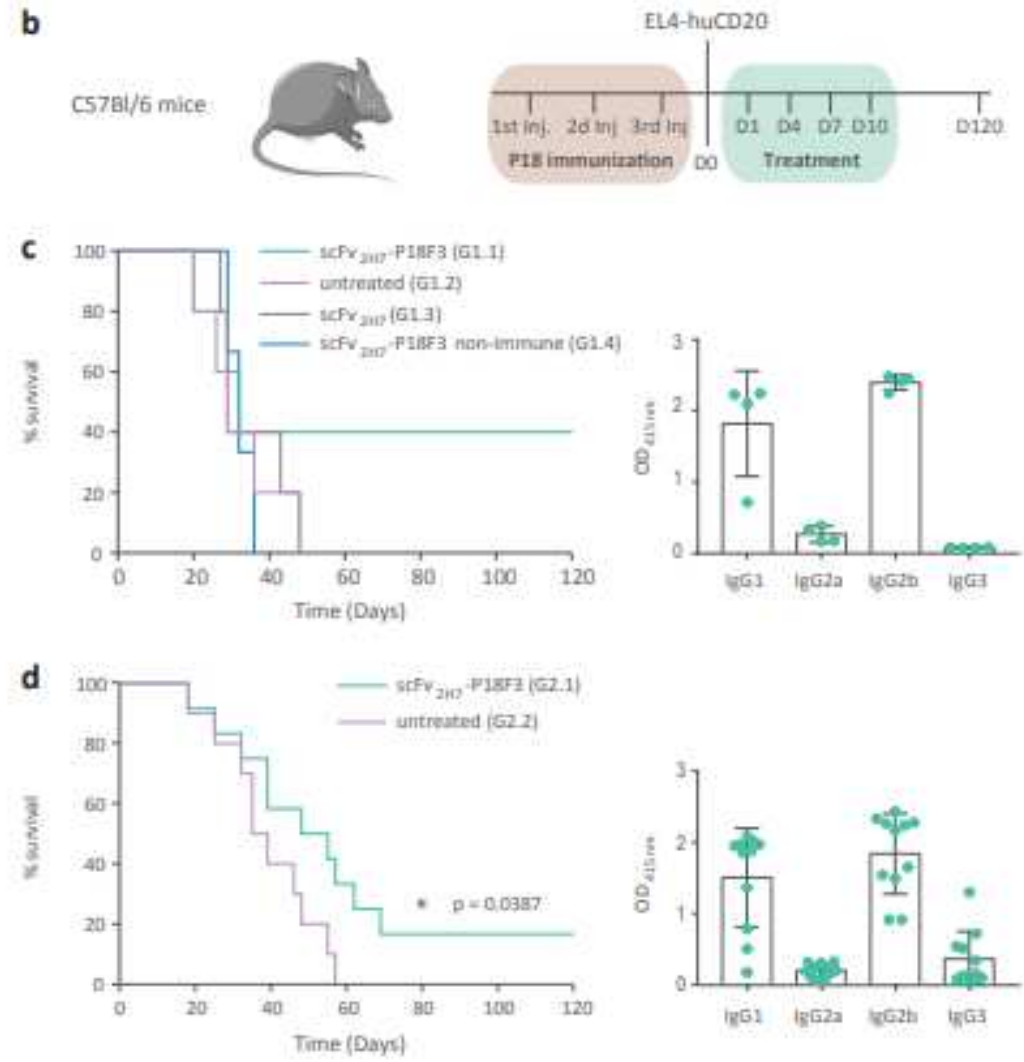

\section{Figure 6}

Treatment with scFv2H7-P18F3 reduces cancer progression in mice bearing EL4-huCD20 tumor cells. (a) Opsonization of scFv2H7- or scFv2H7-P18F3-coated EL4-huCD20 cells by IgG present in the individual sera (dilution 1/10) of 12 BALB/cByJ immunized with MBP-P18. Mouse IgG opsonization was assessed by labeling cells with donkey anti-mouse $\lg \mathrm{G}(\mathrm{Fc})$ conjugated to allophycocyanin (APC) antibodies and 
flow cytometry. Pre-Immu.: Pre-immune serum samples. Immu.: Immune serum samples. Ø: no scFv protein. Results obtained using EL4-WT cells are shown in Supplementary Fig. 11b. (b) The anti-tumor effect of ScFv2H7-P18F3 therapy was assessed in a mouse tumor model in two series of experiments. C57BI/6 mice were pre-immunized with MBP-P18FL with four subcutaneous injections (25 $\mu \mathrm{g}$ MBP-P18FL/injection). Mice were then injected with $2.5 \times 105$ EL4-huCD20 cells at Day 0 (D0) and received ScFv2H7-P18F3 therapy, consisting in 4 intraperitoneal injections at Days 1, 4, 7 and 10 (57 $\mu \mathrm{g}$ scFv2H7$\mathrm{P} 18 \mathrm{~F} 3$ /injection). Mice were followed-up for up to 120 days and were euthanized as soon as one of the following clinical criteria appeared: Presence of tumor on palpation, hindquarters paralysis, prostration, weight loss, hair bristling, abnormal abdominal swelling. (c) Left panel. Four groups (G) of 5 mice were differentially treated. Mice belonging to G1.1 and G.1.4 received scFv2H7-P18F3 therapy but mice from G.1.4 were not pre-immunized with MBP-P18FL (non-immune). Pre-immunized mice from G1.3 received scFv2H7 therapy. Right panel. Anti-P18F3 IgG subclasses were analyzed by ELISA from serum samples collected 2 days before EL4-huCD20 injection into G1.1 mice. OD: Optical Density. (d) Left panel. Two groups of mice were differentially treated. Mice belonging to $\mathrm{G} 2.1(\mathrm{n}=12)$ received scFv2H7-P18F3 therapy whereas mice from G2.2 $(n=11)$ received PBS. Comparison of survival curves was performed using a Log-rank (Mantel-cox) test. $\chi 2=4.275$. The P-value $<0.05$ was considered as statistically significant $\left({ }^{*}\right)$. Right panel. Anti-P18F3 IgG subclasses were analyzed by ELISA from serum samples collected 2 days before EL4-huCD20 injection into G2.1 mice. The art pieces used in the figure are modified from Servier Medical Art by Servier, licensed under a Creative Commons Attribution 3.0 Unported License (https://smart.servier.com/).

\section{Supplementary Files}

This is a list of supplementary files associated with this preprint. Click to download.

- SUPPLEMENTARYFIGURESfinal.pdf 